\title{
Systemic Compensatory Response to Neonatal Estradiol Exposure Does Not Prevent Depletion of the Oocyte Pool in the Rat
}

\author{
Clémentine Chalmey ${ }^{1}$, Franck Giton ${ }^{2,3}$, Frédéric Chalmel ${ }^{1}$, Jean Fiet ${ }^{3}$, Bernard Jégou ${ }^{1,4}$, \\ Séverine Mazaud-Guittot ${ }^{1 *}$
}

1 Institut National de la Santé et de la Recherche Médicale, Unité 1085 Institut de Recherche en Santé Environnement et Travail, Institut Fédératif de Recherche 140, Université de Rennes 1, Rennes, France, 2 AP-HP, Hôpital H. Mondor - A. Chenevier, service de Biochimie et de Génétique, Créteil, France, 3 Institut National de la Santé et de la Recherche Médicale, U955 Équipe 07, Créteil, France, 4 Ecole des Hautes Études en Santé Publique, Rennes, France

\begin{abstract}
The formation of ovarian follicles is a finely tuned process that takes place within a narrow time-window in rodents. Multiple factors and pathways have been proposed to contribute to the mechanisms triggering this process but the role of endocrine factors, especially estrogens, remains elusive. It is currently hypothesized that removal from the maternal hormonal environment permits follicle formation at birth. However, experimentally-induced maintenance of high $17 \beta$ estradiol (E2) levels leads to subtle, distinct, immediate effects on follicle formation and oocyte survival depending on the species and dose. In this study, we examined the immediate effects of neonatal E2 exposure from post-natal day (PND) 0 to PND2 on the whole organism and on ovarian follicle formation in rats. Measurements of plasma E2, estrone and their sulfate conjugates after E2 exposure showed that neonatal female rats rapidly acquire the capability to metabolize and clear excessive E2 levels. Concomitant modifications to the mRNA content of genes encoding selected E2 metabolism enzymes in the liver and the ovary in response to E2 exposure indicate that E2 may modify the neonatal maturation of these organs. In the liver, E2 treatment was associated with lower acquisition of the capability to metabolize E2. In the ovary, E2 depleted the oocyte pool in a dose dependent manner by PND3. In $10 \mu \mathrm{g} /$ day E2-treated ovaries, apoptotic oocytes were observed in newly formed follicles in addition to areas of ovarian cord remodeling. At PND6, follicles without any visible oocyte were present and multi-oocyte follicles were not observed. Our study reveals a major species-difference. Indeed, neonatal exposure to E2 depletes the oocyte pool in the rat ovary, whereas in the mouse it is well known to increase oocyte survival.
\end{abstract}

Citation: Chalmey C, Giton F, Chalmel F, Fiet J, Jégou B, et al. (2013) Systemic Compensatory Response to Neonatal Estradiol Exposure Does Not Prevent Depletion of the Oocyte Pool in the Rat. PLOS ONE 8(12): e82175. doi:10.1371/journal.pone.0082175

Editor: Jae-wook Jeong, Michigan State University, United States of America

Received July 12, 2013; Accepted October 21, 2013; Published December 16, 2013

Copyright: (c) 2013 Chalmey et al. This is an open-access article distributed under the terms of the Creative Commons Attribution License, which permits unrestricted use, distribution, and reproduction in any medium, provided the original author and source are credited.

Funding: C. Chalmey is funded by Region Bretagne (Doctoral research grant \#10022). This study was funded by Inserm, University Rennes 1 (Défits scientifiques émergents -2010) and Rennes Metropole (\#10-705). The funders had no role in study design, data collection and analysis, decision to publish, or preparation of the manuscript.

Competing Interests: The authors have declared that no competing interests exist.

*E-mail: severine.mazaud@univ-rennes1.fr

\section{Introduction}

Mammalian birth is characterized by dramatic endocrine changes and, in female rodents, this occurs concomitantly with crucial morphogenetic processes in the ovaries. The formation of ovarian follicles that occurs in the days following birth, will determine the whole reproductive life of the female. Although a fetus is likely to be exposed to high levels of steroids (in particular progesterone and estradiol [1,2]), the maternal liver and excretory organs manage their biotransformation and elimination. The fetus is also protected by the placental barrier and by binding proteins. Circulating steroids undergo a rapid decrease in the days following birth and reach nadir at the end of the first week until the newborn synthesizes its own steroids at the beginning of the infantile period [1-6]. This sudden release from maternal hormonal impregnation is associated with a rapid increase in the expression and activity of enzymes involved in hormone metabolism and detoxification machinery in the newborn liver $[7,8]$. As a consequence, the newborn acquires the capability to metabolize a variety of hormones and xenobiotics during the first week of life.
In the ovary, the formation of functional units (the follicles) from the immature fetal ovarian cords also takes place within the three days following birth $[9,10]$. Ovarian cords are composed of clusters of germ cells progressing through the first prophase of meiosis, surrounded by pregranulosa cells, and delineated by a continuous basal membrane. They fragment thanks to the deposition of a new basement membrane [11]. This fragmentation is associated with the separation of oocytes, which remained interconnected as nests or cysts during synchronous mitosis $[9,10]$, and with a massive wave of degeneration specifically targeting oocytes resulting from both apoptotic and autophagic mechanisms [12-15]. A number of factors, mechanisms and pathways have been suggested to be involved in follicle formation. These include the endogenous meiosis clock, central signals and neurotrophic factor signaling, growth factor signaling (especially those of the transforming growth factor family) and transcription factors (for review, [10]). In addition, several studies have highlighted endocrine factors such as progesterone and $17 \beta$-estradiol (E2) as candidate actors of follicle histogenesis in several specie from mice, 
rats to cattle and primates [4,16-18]. It is currently hypothesized that the decrease in maternal E2 impregnation that follows birth permits oocyte cyst breakdown, and consequently, follicle formation. Therefore, maintenance of high E2 levels or exposure to E2mimicking molecules may result in inhibition of oocyte cyst breakdown. However, experimentally-induced high neonatal E2 levels have subtly-diverging immediate effects depending on the species (and even strains) in terms of oocyte survival and ovarian cord fragmentation, i.e. follicle formation. High post-natal E2 levels increase oocyte survival but inhibit follicle formation in mice $[4,18]$. However, they promote both follicle formation and oocyte survival in the hamster $[19,20]$. In the baboon, maintenance of maternal E2 levels are required for follicle formation since a treatment with an aromatase inhibitor leads to a sharp inhibition of the process [21]. In the rat, E2 moderately inhibits follicle assembly but increases primordial-to-primary follicle transition in vitro and leads to hypoplastic ovaries from post-natal day (PND) 4 onward [16,22]. A typical feature of neonatal exposure to E2 or xeno-estrogens such as diethylstilbestrol (DES), bisphenol A (BPA) and genistein (GEN) is a high incidence of multi-oocyte follicles (MOFs) in peripubertal mice and rats [18,23-28]. Although these MOFs are thought to arise from reduced oocyte cysts breakdown, oocyte apoptosis and/or basement membrane neosynthesis and deposition, the fine etiology of this morphogenetic abnormality and the role of estrogenic compounds are still obscure.

Increasing concerns of xeno-estrogens impact on health have led to experimental studies using compounds displaying various estrogenic activities (DES, BPA, GEN ...). The use of E2 or estradiol-like molecules with distinct kinetic properties (including ethinyl estradiol, estradiol-benzoate, estradiol-valerate and estradiol-cypionate) as reference molecules has increased the complexity of this issue. Although E2 is widely used as a reference molecule in comparisons with xeno-estrogens, its own mechanism of action is not completely understood. In addition, due to the availability of transgenic mice, many studies addressing the effects of a neonatal exposure to E2 and xeno-estrogens on follicle formation have been carried out using mice. Although the rat has often been the model of choice to study molecules affecting the sexual differentiation of the central nervous system $[29,30]$, the direct effects of neonatal E2 exposure to the ovary remains unclear in this species.

As a consequence, the aim of this study was to better clarify the immediate adverse effects of E2 on the ovary in the rat. To that purpose, we injected newborn pups with E2 during the short time window corresponding to follicle formation. As a prerequisite for an acute evaluation of E2 exposure and in an attempt to define effective doses, we examined dose-effects using doses between $10 \mu \mathrm{g} /$ day/animal and $0.01 \mu \mathrm{g} /$ day/animal and compared the dynamics of the resulting plasma E2 in the pups. To gain insights into the fate of E2, we also evaluated dynamics of circulating metabolites and the effects of E2 treatment on the expression of the enzymes of the detoxification machinery in the newborn liver. In the ovary, we searched for detoxification capabilities and evaluated the impact of E2 exposure on: i) these possible local metabolizing capabilities, ii) oocyte survival and iii) follicle formation.

\section{Materials and Methods}

\section{Ethic Statement}

The animal facility is licensed by the French Ministry of Agriculture (agreement \# C 35-238-19). All the experimental procedures followed ethical principles according to the NIH Guide for Care and Use of the Laboratory Animals and were approved by the Rennes Animal Experimentation Ethics Committee (\#R2012-CCh-01).

\section{Animal Handling and Treatments}

Adult Sprague-Dawley rats were conventionally housed at adequate temperature $\left(22 \pm 5^{\circ} \mathrm{C}\right)$ and humidity (around $55 \%$ ) with 12:12 h light/dark cycles and free access to food and tap water. Their food contained soy (Special Diets Services, Witham, England). Females were mated overnight with males. The following day was considered to be embryonic day $0(\mathrm{e} 0)$. Pregnant females were isolated three days before birth, which generally occurs at e22.5. Newborn females received a subcutaneous injection of $17 \beta$-estradiol or corn oil (vehicle-negative control) (Sigma Aldrich) within a few hours after birth (PND0) and on two subsequent days (PND1 and 2). Animals were divided in five groups: one group received the negative control and four experimental groups received $0.01,0.1,1$ or $10 \mu \mathrm{g} /$ day of $17 \beta$ estradiol.

\section{Organs and Plasma Collection}

Animals were killed by decapitation in the morning of PND0, 1, 2, 3 or 6 . Trunk blood was collected into heparinized tubes and centrifuged, and plasma was kept frozen $\left(-20^{\circ} \mathrm{C}\right)$ until steroid hormone assay. Ovaries were collected at each age, separated from the ovarian capsule and fixed overnight in Bouin's solution for immunohistochemistry or in $2 \%$ paraformaldehyde-PBS $\left(\mathrm{pH} \mathrm{7.2)}\right.$ for $1 \mathrm{~h}$ at $4^{\circ} \mathrm{C}$ for in situ hybridization. Livers and ovaries were removed and snap frozen for RNA extraction.

\section{Hormone Measurements}

Serum samples from two or three animals were pooled and randomized before assaying. Estrone (E1), estradiol (E2), estronesulfate (E1-S) and estradiol-sulfate (E2-S) were assayed in two steps using mass spectrometry coupled with gas chromatography [31,32]. Sera were overloaded with deuterated steroid internal standards (CDN isotopes Inc., Canada) and extracted with 1chlorobutane. The organic extracts were purified on conditioned LC-Si SPE columns (Varian, Les Ulis, France). E1 and E2 were derivatized with pentafluorobenzoyl chloride (103772-1G, Aldrich, Steinheim, Germany). The final extracts were reconstituted in isooctane and transferred into conical vials for injection into the GC system (6890N, Agilent Technologies, Massy, France) using $50 \%$ phenylmethylpolysiloxane VF-17MS capillary columns (20 $\mathrm{m} \times 0.15 \mathrm{~mm}$, internal diameter, $0.15 \mu \mathrm{m}$ film thickness) (Varian, Les Ulis, France). An HP5973 (Agilent Technologies, Massy, France) quadrupole mass spectrometer equipped with a chemical ionization source and operating in single ion monitoring (SIM) mode was used for detection. E1-S and E2-S retained in the aqueous phase of the extraction were measured after acid solvolysis as E1 and E2, respectively [33]. Accuracy, target ions, corresponding deuterated internal control, range of detection, low limit of quantification (LLOQ), and intra \& inter assay CVs of the quality control serums are reported in table $\mathrm{S} 1$.

\section{In situ Hybridization and Coupled Immunofluorescence}

Fixed ovaries were cryoprotected in $20 \%$ (wt/vol) sucrose in PBS for $1 \mathrm{~h}$, embedded in Tissue-Tek OCT compound (Miles, Inc., Elkhart, IN), cut into $8 \mu \mathrm{m}$-thick sections, mounted onto 3aminopropyltriethoxysilane-treated glass slides (Sigma-Aldrich Corp., St. Louis, MO) and stored at $-20^{\circ} \mathrm{C}$. The cDNAs used for synthesis of the different riboprobes were obtained by RT-PGR and subcloned into pGEMT easy $_{\text {(Promega). The nucleotide }}$ sequences were verified by sequencing. Primers and product 
lengths are given in Table 1. Riboprobes were generated by transcription with digoxigenin-labeled deoxy-UTP and the appropriate SP6 or T7 RNA polymerase (Roche). In situ hybridization on frozen sections was carried out as previously described [5]. Detection of apoptotic cells was performed on sections previously treated for Ybx2 in situ hybridization using the in situ cell death detection kit, Fluorescein (terminal deoxynucleotidyltransferase-mediated deoxy-uridine $5^{\prime}$-triphosphate-fluorescein nick end labeling (TUNEL), Roche). After PBS washing, sections were incubated with the TUNEL reaction mixture containing terminal transferase for $1 \mathrm{~h}$ at $37^{\circ} \mathrm{C}$. For double labeling of sections (if appropriate after detection of $\mathrm{Ybx} 2$ or Gper mRNA by in situ hybridization), sections were rinsed in PBS and incubated overnight at $4^{\circ} \mathrm{C}$ with Esr2 (Biogenex, AR385-5R, RTU), fibronectin (Sigma Aldrich, F3648, 1:100) or Ybx2 (Santa Cruz Biotechnologies, Inc. Santa Cruz, CA, sc-21316, 1:200) antibodies. An antigen retrieval procedure was necessary before Esr2 antibody incubation $\left(10 \mathrm{mM}\right.$ citrate buffer, $\mathrm{pH} 6$, at $80^{\circ} \mathrm{C}$ for $45 \mathrm{~min}$ ). After washing, sections were incubated with secondary 488- or 594-Alexa anti-rabbit (Esr2, fibronectin) or anti-goat (Ybx2) antibodies (IgG Alexa antibodies, Invitrogen, 1:500). The second primary antibody was incubated overnight with the sections at $4^{\circ} \mathrm{C}$, and the second antigen/antibody complex was then reacted with the appropriate secondary antibody. For TUNEL associated with fibronectin detection, the TUNEL reaction was performed as described and followed by fibronectin labeling. Fluorochrome-labeled sections were mounted in Vectashield ${ }^{\circledR}$ containing the DNA stain DAPI (Vector Laboratories), and analyzed with a Zeiss Axio Imager M1 fluorescence microscope connected to a digital camera (Carl Zeiss New York, $\mathrm{NY})$.

\section{Stereological Counts}

For oocyte counts, PND0, 1, 2 and 3 ovaries were fixed with Bouin's solution, dehydrated and paraffin embedded according to standard procedures. One out of every five $5 \mu \mathrm{m}$ sections were mounted with albumin on TESPA-treated glass slides. After dewaxing and rehydration, an antigen retrieval procedure was performed with citrate buffer $10 \mathrm{mM} \mathrm{pH} 6$ at $80^{\circ} \mathrm{C}$ for $45 \mathrm{~min}$. Unspecific sites were saturated with 10\% Bovine Serum Albumin (BSA)-PBS and the sections were incubated overnight at $4^{\circ} \mathrm{C}$ with the primary antibody (Gena, clone TRA98, Clinisciences, 1:100 diluted in Dako antibody diluent). After washes in PBS, sections were reacted with a biotinylated secondary antibody (Sigma Aldrich; 1:500 in PBS) and incubated for 4 h at room temperature. An avidin-biotin complex linked to a peroxidase (Vectastain Elite ABC kit, Vector Labs) was used to bind to diaminobenzidine, a peroxidase substrate (Sigma Aldrich). Sections were counterstained with Masson's Hemalun, dehydrated and mounted in Eukitt (Kindler GmbH). For total oocyte counts, Gena/TRA98positive cells were counted by using the Computer-Assisted Stereology Toolbox (CAST) Grid System (Olympus, Copenhagen, Denmark) on a light microscope (Olympus BX S1). At first, we delineated the ovarian borders at low magnification. The ovarian volume was deducted by multiplying the sum of the surfaces of each section by the thickness of the sections $(5 \mu \mathrm{m})$ and another time by 5 because measurement was done every fifth sections. Then, we counted the immunopositive cells using the oocyte nucleus as a marker at 100X using a high-numerical-aperture objective lens on each section. All oocytes were added together to reflect an estimation of the total oocyte number per ovary. For dying oocyte counts, apoptotic cells were detected by the TUNEL technique using the Apoptag cell kit (Millipore, S1700) according to manufacturer's instructions. TUNEL-positive oocytes were counted in every fifth section and added together to give the total apoptotic oocytes per ovary. Stained sections were examined under a light microscope (Olympus BX51).

\section{RNA Extraction and Polymerase Chain Reaction (PCR)}

RNA extractions from ovaries and livers were carried out with a Nucleospin XS kit (Macherey Nagel; 740902) according to manufacturer's instructions. Total RNAs (250 ng) were reverse transcribed with random primers and Moloney Murine Leukemia Virus Reverse Transcriptase (Invitrogen). Conventional PGR was performed using Taq polymerase (Qiagen) in a Peltier thermocycler (MJ Research, Bio-Rad DNA engine) using the primers listed in Table 1. PCR consisted of an initial denaturation at $94^{\circ} \mathrm{C}$ for $3 \mathrm{~min}, 35$ (or 42 in the case of Sultlel) cycles of $94^{\circ} \mathrm{C}$ for $30 \mathrm{~s}$, $1 \mathrm{~min}$ of annealing, $72^{\circ} \mathrm{C}$ for $30 \mathrm{~s}$ and a $10 \mathrm{~min} 72^{\circ} \mathrm{C}$ final extension. Quantitative PCR was performed using the GoTaq ( Master mix (Promega) according to manufacturer's instructions with $0.5 \mu \mathrm{l}$ cDNA template in an Applied Biosystems 7500 RealTime PCR system. The following amplification program was used: a 2 min holding stage at $50^{\circ} \mathrm{C}$, initial denaturation of $10 \mathrm{~min}$ at $95^{\circ} \mathrm{C}, 40$ cycles of $1 \mathrm{sec}$ amplification at $95^{\circ} \mathrm{C}$ and $1 \mathrm{~min}$ at $60^{\circ} \mathrm{C}$ for annealing and extension. Dissociation curves were produced using a thermal melting profile performed after the last PCR cycle. To avoid amplification of contaminating genomic DNA, primer pairs were selected on either side of an intron. Snx 17 mRNA was used as an internal control for normalization. Results were expressed by $\Delta \Delta \mathrm{CT}$ method as $n$-fold differences in target gene expression, relative to the reference gene and calibrator sample which is constituted of an equal mixture of all the samples tested specifically in each tested organ.

\section{Data Analysis}

Microarray data analysis was carried out on datasets from Kezele et al, [34], GSE 9300 (GSM237013-237016) using the Annotation, Mapping, Expression and Network (AMEN) analysis software [35]. GeneChip data were normalized using the Robust Multi-Array Average (RMA) method and the resulting expression values for ovary replicates at PND0 and PND4 were averaged. Probe sets yielding a signal higher than the detection threshold (median of the normalized dataset, cutoff 7.47), and a fold-change $\geq 1.5$ between PND0 and PND4 averaged ovary samples, were selected. A Linear Model for Microarray Data (LIMMA) statistical test (F-value adjusted with the False Discovery Rate method: $\mathrm{p} \leq 0.05)$ was used to identify probe sets with significantly different expression. For further classification, we divided the selected probe sets into groups being significantly decreased or increased in PND4 ovary samples as compared to PND0. We restricted our subsequent analysis to probe sets corresponding to genes associated with the "steroid metabolic process" Gene Ontology annotation term (GO:0008202).

\section{Statistical Analysis}

Quantitative PCR data and cell counts are presented as mean \pm SEM. Blood and ovaries for quantitative PCR from different animals were pooled to form one sample and several pools from different litters were used for a given treatment and time point. The sizes of the pools are given in each figure legend. For oocyte counts, 4-13 ovaries were used, as specified for each parameter in the corresponding figure legend. An analysis of the variance (oneway or two-ways ANOVA) followed by the appropriate post-hoc test was used to compare differences between groups, as specified in each figure legend. Significance was accepted at a confidence level of $\mathrm{p} \leq 0.05$. Statistical analyses were performed using the 
Table 1. Primers used for $\mathrm{qPCR}$ and in situ hybridization $(*)$.

\begin{tabular}{|c|c|c|c|c|}
\hline Gene & Upstream primer & Downstream primer & Product length (bp) & Annealing $\mathbf{T}^{\circ} \mathrm{C}$ \\
\hline Bax & CTAGCAAACTGGTGCTCAAGG & GGAGGAAGTCCAGTGTCCAG & 84 & 60 \\
\hline $\mathrm{BCl} 2$ & AACATCGCTCTGTGGATGACT & ACAGCCAGGAGAAATCAAACA & 133 & 60 \\
\hline Сур1b1 & GCAGCCGCCTTCCTGGTAGC & CCACGCGCCCTGTCCCTACT & 116 & 60 \\
\hline Сур2b1/2 & ATGTTTGGTGGAGGAACTGC & CTGGCGGTCTGTGTAGTCAA & 130 & 63 \\
\hline Eif4e & AGCAATATGGACGACTGAATGTGA & TGTCTGCGTGGGACTGATAACC & 119 & 60 \\
\hline Esr1 & GATCAAGTTCACCTTCTGGA & AGCAAGTTAGGAGCAAACAG & 107 & 60 \\
\hline Esr1 * & CTACAGGTCCAATTCTGACA & TGGAGACATGTAGTCATTATG & 220 & 58 \\
\hline Esr2 & GAAGCTGAACCACCCAATGT & CAGTCCCACCATTAGCACCT & 210 & 60 \\
\hline Esr2 * & ACGGTGGGCATGCACCCC & GCCAATCATGTGCACCAG & 201 & 58 \\
\hline Figla & ATGGACACGTCGTCGCCTGC & TGGCCACCATACGCCCAAGG & 524 & 60 \\
\hline Foxa3 & ATGCTGGGCTCAGTGAAGAT & GGGAGAGCTAAGAGGGTTCAA & 147 & 60 \\
\hline Gper & TCTACCTAGGTCCCGTGTGG & AAGCTCATCCAGGTGAGGAA & 418 & 60 \\
\hline Gper * & TCTACCTAGGTCCCGTGTGG & AAGCTCATCCAGGTGAGGAA & 418 & 58 \\
\hline Gsta2 & GGCAAAAGACAGGACCAAAA & GGCTGCAGGAACTTCTTCAC & 231 & 62 \\
\hline Gstm5 & GGTTTGCAGGAGAAAAGCTG & TGATTGGCATCTTGAAGCAG & 186 & 62 \\
\hline Gstp1 & GGGCATCTGAAACCTTTTGA & GAGCCACATAGGCAGAGAGC & 175 & 63 \\
\hline Hnrnpk & TGCTGATGAAACTTGGGACTCTG & CGAATTTGTTAATCCGCTGACC & 222 & 60 \\
\hline Hsd17b2 & GACAAAGGACTGTGGGCTGT & AACACCTTGGTGACCTCGAC & 137 & 60 \\
\hline Nobox & GAAGACATGGGACCTCAGGA & GCCGAAAGGAAATGAAAACA & 192 & 60 \\
\hline $\mathrm{Nr} 1 \mathrm{i} 2$ & GACGGCAGCATCTGGAACTAC & TGATGACGCCCTTGAACATG & 112 & 60 \\
\hline Rbp4 & GGACGAGTCCGTCTTCTGAG & AAAGGAGGCTACACCCCAGT & 114 & 60 \\
\hline Scp1 & AGCTTTTGGGAGAGGTTGAGAA & TCAGCTATTTTATGTTGGCATCGT & 97 & 62 \\
\hline Snx17 & ССTCTACCCAAGAGGAGATTTATACAA & CCAAGAGGGAACAGAACAAGT & 100 & 60 \\
\hline Sult1e1 & GTGGAAAAATGCAAGGAGGA & GCTTAGCTGGCAGGTGAGTT & 139 & 58 \\
\hline Ugt1a1 & ACACCGGAACTAGACCATCG & TTGGAACCCCATTGCATATT & 153 & 62 \\
\hline Ybx2 * & САССTCССTСТTСTATCGA & GGTGATGCCTCTGAACAATA & 637 & 58 \\
\hline
\end{tabular}

SigmaStat 2.0 software package (Systat Software Inc, San Jose, CA).

\section{Results}

\section{Response of the Whole Organism to E2 Exposure}

Besides its biological activity involving by binding to receptors and subsequent transcriptomic activity, E2 is transformed into several possible metabolites before excretion (Fig. 1A). To monitor the dynamics of plasma E2 levels after E2 treatment in comparison to physiological levels, we measured E2 levels in rat neonates at PND0 (before injections) and $16 \mathrm{~h}$ after each injection on days PND1 to PND3 and PND6 (Fig. 1B). The mean E2 levels significantly decreased after birth in control females and drastically dropped at PND6. All treated groups followed the same trend, except the $0.01 \mu \mathrm{g}$ group which did not differ from controls. E2 plasma levels increased at PND1 following the first injection of E2 (statistically significant in only the $10 \mu \mathrm{g} / \mathrm{d}$-treated group), but significantly decreased until PND3 in spite of repeated injections. Plasma E2 levels of the $10 \mu \mathrm{g} / \mathrm{d}$-treated group did not return to baseline at PND3 but were the same as control levels from PND6 onwards.

To explore the fate of $\mathrm{E} 2$ in the females, we quantified the presence of several major E2 metabolites (estradiol-sulfate (E2-S), estrone (E1), and estrone-sulfate (E1-S)), at the same time points (Fig. 1B-E). Estriol (E3), another natural E2 metabolite, was also assayed but all the samples displayed concentrations below the detection limit $(10 \mathrm{pg} / \mathrm{ml})$. In contrast to E2, E2-S remained constant in all samples, irrespective of the huge raise in E2 levels in the $10 \mu \mathrm{g} / \mathrm{d}$ group (Fig. 1C). Time, but not treatment, had a significant effect on E2-S level $(\mathrm{P}<0.001)$. E1 profiles were highly similar to those of $\mathrm{E} 2$ in accordance with the injected dose (Fig. 1D). The higher E1 levels at PNDl were statistically significant in the $10 \mu \mathrm{g} / \mathrm{d}$ and $1 \mu \mathrm{g} / \mathrm{d}$ groups. Similar to E2, E1 levels dramatically dropped at PND6 with time and treatment having independent effects. E1-S peaked at PND3, and this increase was significant in the $10 \mu \mathrm{g} / \mathrm{d}$ and $1 \mu \mathrm{g} / \mathrm{d}$ groups. In all groups, plasma E1-S levels decreased between PND3 to PND6 (Fig. 1E). The two-way analysis of variance revealed that the variation of all metabolite levels was statistically correlated with time, independently of treatment. The dose of injected E2 significantly affected the mean values of all metabolites except E2-S. The multiple comparison procedure identified the E2 $10 \mu \mathrm{g} / \mathrm{d}$ group as different.

The increase in E1 levels after E2 injections suggested a metabolic conversion between those two forms. We therefore investigated variation in the expression of $H s d 17 b 2$, and of several phase-I and phase-II enzymes involved in hepatic detoxification of estrogens (Ugt1a1, Cyp1b1, Cyp2b1/2 and Gsta2), in response to $10 \mu \mathrm{g} / \mathrm{d}$ E2 by quantitative PCR in the liver (Fig. 1F-J). mRNA levels of $H s d 17 b 2$ and $C y p 2 b 1 / 2$ increased from PND0 to PND1 in the control group but there was no variation in the E2-treated 
A

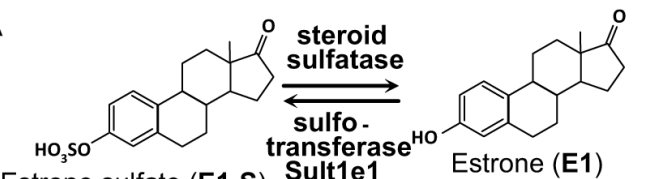

Estrone sulfate (E1-S)

Sult101

Estrone (E1)

Hsd17b2 \Hsd17b1

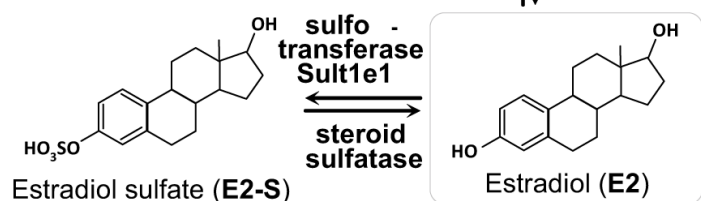

UDP-glucuronosyl

transferase

Estradiol sulfate (E2-S)

Estradiol (E2)
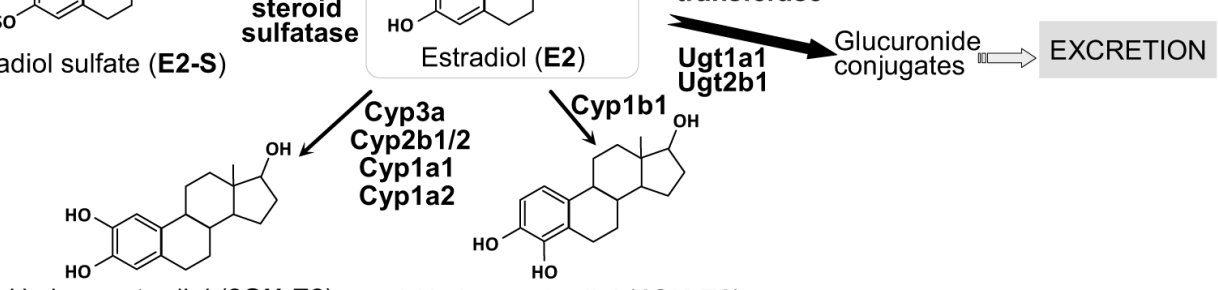

2-Hydroxyestradiol (2OH-E2)

COMT

2-Methoxy

estradiol

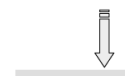

EXCRETION

4-Hydroxyestradiol (4OH-E2)

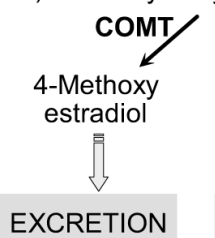

P450R

Estradiol 3,4- glutathion-S-

semiquinone transferase

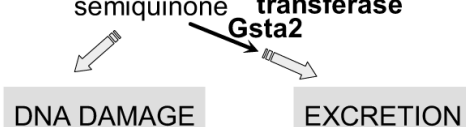

RECEPTOR

BINDING

(1)

ACTIVITY
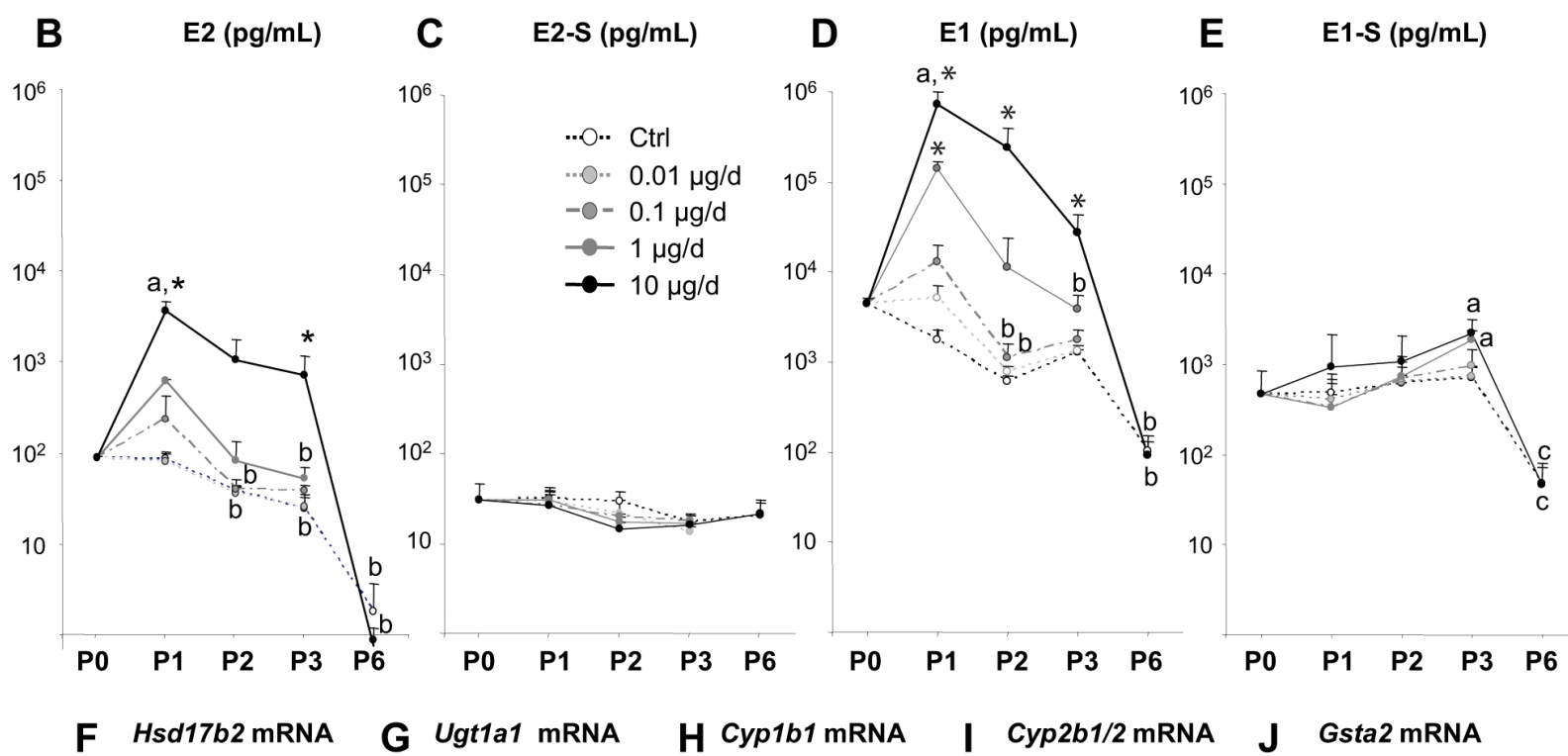

I Cyp2b1/2 mRNA

\section{J Gsta2 mRNA}
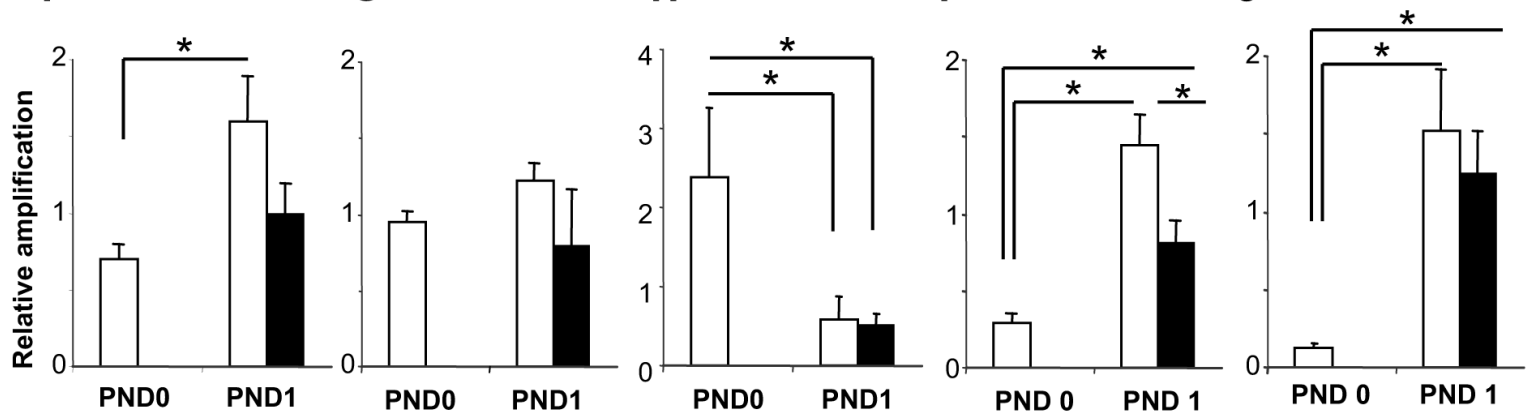

Figure 1. Plasma and hepatic reaction to acute estrogen exposure. A. Representative scheme of E2 biological activity and detoxification pathways. E2 can go through oxidative metabolism and be converted in E1 by $17 \mathrm{bHsd} 2$ or in hydroxyl-metabolites by enzymes of the Cyp family. Then it can be methylated by COMT, reduced by P450 reductase (resulting in DNA damage) or excreted after conjugative metabolism by GST. E2 can 
also be directly sulfo-conjugated by SULT or gluco-conjugated by UGT, and excreted. B-E. Plasma estradiol (B) and derivatives E2-sulfate (E2-S; C), estrone (D) and estrone-sulfate (E1-S; E) were measured by GC/MS from the day of birth (P0) to PND6 (P6). Each point represents the mean \pm SEM of at least four pools of two animals each. A two-way ANOVA indicated that there was a significantly different profile for the $10 \mu \mathrm{g} / \mathrm{d}$ E2 treatment than for all other treated or control groups $(p<0.001), E 1(p<0.001), E 1-S(p=0.002)$. Hormonal levels varied according to time, independent of treatment, for each metabolite tested: E1 $(p<0.001)$, E2 $(p<0.001)$, E1-S $(p<0.001)$ and E2-S $(p<0.001)(n=4-5$ pools of 3 to 4 animals at PND0, 4-5 pools of 2-4 animals at PND1, 4 pools of 2-3 animals at PND2, 4 pools of 2 animals at PND3 and 8 animals at PND6). F-J. Quantitative RT-PCR for Hsd17b2 (F), Ugt1a1 (G), Cyp1b1 (H), Cyp2b1/2 (I) and Gsta2 (J) using liver samples of controls (white bars) and animals treated with $10 \mu \mathrm{g}$ E2 at PND0 and PND1 (black bars) shows E2 impairment on post-natal Hsd17b2, Cyp2b1/2 and Gsta2 expression dynamics. Each bar represents mean \pm SEM of the foldchange in target gene expression relative to a reference gene Snx17 and calibrator sample. Each point represents mRNA from 3 pools of ovaries from 3 animals. ${ }^{*}<0.05$ (two-way ANOVA, followed by Tukey test). a shows an increase from PND0, $\mathbf{b}$ shows a decrease from PND1, $\mathbf{c}$ shows a decrease from PND3 and * shows a difference from the age-matched control group.

doi:10.1371/journal.pone.0082175.g001

group (Fig. 1F, I). Ugt1a1 levels did not vary significantly with age or treatment (Fig. 1G). The levels of Cyp1b1 mRNA (Fig. 1H) were lower at PNDl than at PND0 and treatment had no effect. In contrast, the levels of Gsta2 mRNA were higher at PND1 than at PND0 in $10 \mu \mathrm{g} / \mathrm{d}$-treated and control animals (Fig. 1J).

\section{Ovarian Estrogen Receptivity in Response to E2 Exposure}

Regulation of expression of the well known-nuclear estrogen receptors, i.e. Esr1, Esr2, of the membranous estrogen receptor Gper and of the nuclear receptor $\mathcal{N r} 1 i 2$, which can bind estrogens and whose expression is regulated at birth in mouse ovary [36,37] was assessed around the time of treatment by quantitative PCR (Fig. 2A-D). The expression of Esr 1 mRNA significantly decreased between el8.5 and PND12 (Fig. 2A), while expression of Esr2 mRNA was low at e18.5 and significantly increased from birth to PND12 (Fig. 2B). Gper and Nr1i2 mRNA had similar ageassociated expression profiles (Fig. 2C-D).

We investigated which ovarian cell types expressed estrogen receptors around the time of treatment and in later development in ovarian sections using in situ hybridization (Fig. 2 E-P, M) and immunofluorescence (Fig. 2 M-O). From PND1 on, we observed a strong Esr1 mRNA signal in the epithelium of the differentiating oviduct (Ovd in Fig. 2E) and a close-to background signal in the ovary (Fig. 2E, H and Figure S1). Esr2 mRNA was expressed in the epithelium of the differentiating oviduct as well as in the ovary (Fig. 2F) and its expression increased in granulosa cells with follicle growth at PND6 (Fig. 2 F, I and K). Gper mRNA expression pattern was very similar to that of Esr2 (Fig. $2 \mathrm{G}, \mathrm{J}$ and L). The comparison of Gper mRNA and Esr2 protein labeling with the oocyte marker Ybx2 showed that oocytes expressed both receptors (Fig. $2 \mathrm{~L}-\mathrm{O}$ ). These data suggest that some Esr 1, and to a greater extent Esr2 and Gper, were expressed in the oocytes and (pregranulosa cells at the time of estrogen injections.

Since estrogen receptors themselves have been described as direct target of estrogens, we measured the profile of expression of their transcripts in response to a $10 \mu \mathrm{g}-\mathrm{E} 2$ exposure (Fig. $2 \mathrm{~N}-\mathrm{Q}$ ). Quantitative PCR at PND0, between 2 and $4 \mathrm{~h}$ after injection, and at PNDl was carried out to investigate the early transcriptomic response of the ovary. Esr1 had a stable expression between PND0 and PND1 and treatment did not affect its expression (Fig. 2N). Similarly, Esr2 had a stable expression in the control group between PND0 and PND1 and, although E2 treatment tended to increase the expression between PND0 and PND1, this did not reach statistical significance (Fig. 2O). Expression levels of Gper significantly increased between PND0 and PND1 in the control group but remained unchanged in the E2-treated group (Fig. 2P). A similar post-natal increase in $\mathcal{N r} 1$ i2 mRNA expression was found in control ovaries but not observed in E2-treated ovaries (Fig. 2Q).

\section{Modifications of Ovarian Metabolic Capabilities in Response to E2}

To get insights into the expression of enzymes of the E2 metabolic pathway in the post-natal ovary, we explored already published transcriptomic profiles of PND0 compared to PND4 rat ovaries [34]. We restricted our analysis to the 227 probe sets (transcripts) associated with the GO term annotation "steroid metabolic process" (GO:0008202). Out of the 133 probe sets with detectable intensity signals in either PND0 or PND4, 114 transcripts did not display differential expression. However, we found 12 to be associated with a significantly increased expression pattern from PND0 to PND 4, and four to be associated with a significantly reduced expression pattern (Fig. 3A). Enzymes involved in E2 biosynthesis increased after birth (statistically significant differences in mRNA expression for Star and Hsd3b1, but not significant for Cyp17a1 and Hsd17b1). This may well correlate with the very first steps of theca-interstitial tissue differentiation. In contrast, mRNAs encoding enzymes involved in E2 transformation such as Sult1a1 and, to a lesser extent, Hsd17b2, and Cyp1b1 decreased in prevalence between PND0 and PND4 (Fig. 3A). Because the microarrays used in this study covered approximately half of the known protein-coding genes, data were partial. We thus selected enzymes of each branch of E2 detoxification pathway to compare by quantitative PCR their expression in PND0 and PND1 neonatal and adult ovaries as well as in PND0 livers (Fig. 3B). The mRNA levels of Hsd1 7b2, Cyp1b1, Cyp2b1/2, Gsta2 and Gstp1 were globally constant over time. By contrast, Sult1e1, Ugt1a1 and Gstm5 were preferentially expressed in the neonatal ovary and merely absent in the adult organ. Of note, Ugt1a1 and Gstm 5 were preferentially expressed in the ovary while Cyp2b1/2 was preferentially expressed in the liver, thus highlighting different pathways of detoxification in each organ. Altogether, these results suggest that the ovary possesses the machinery to locally metabolize E2.

We used quantitative PCR to investigate variation in the expression of selected estrogen metabolism enzymes in response to E2 exposure (Fig. 3 C-F). The expression of $H s d 17 b 2$ was similar in the control and treated groups at PND0. Whereas it remained constant at PND1 in the control group, E2 treatment induced a significant increase in expression in the treated group (Fig. 3C). Cyp1b1 mRNA levels did not vary $2 \mathrm{~h}$ after the $\mathrm{E} 2$ injection (Fig. 3D). However, whereas Cyp1b1 mRNA levels increased significantly between PND0 and PND1 in the control group, they remained unchanged in the treated group (Fig. 3D). The expression of Cyp2b1/2, which was slightly greater in the control group than in the treated group at PND0, dramatically increased between PND0 and PND1 in control group but did not significantly change in the E2-treated group (Fig. 3E). Expression of Gsta2 did not vary in the control group, but significantly increased in the treated group between PND0 and PND1 (Fig. 3F). Ugt1a1 mRNA profile was not modified with either time or treatment (Fig. 3G). Rbp4, which has previously been shown to be 

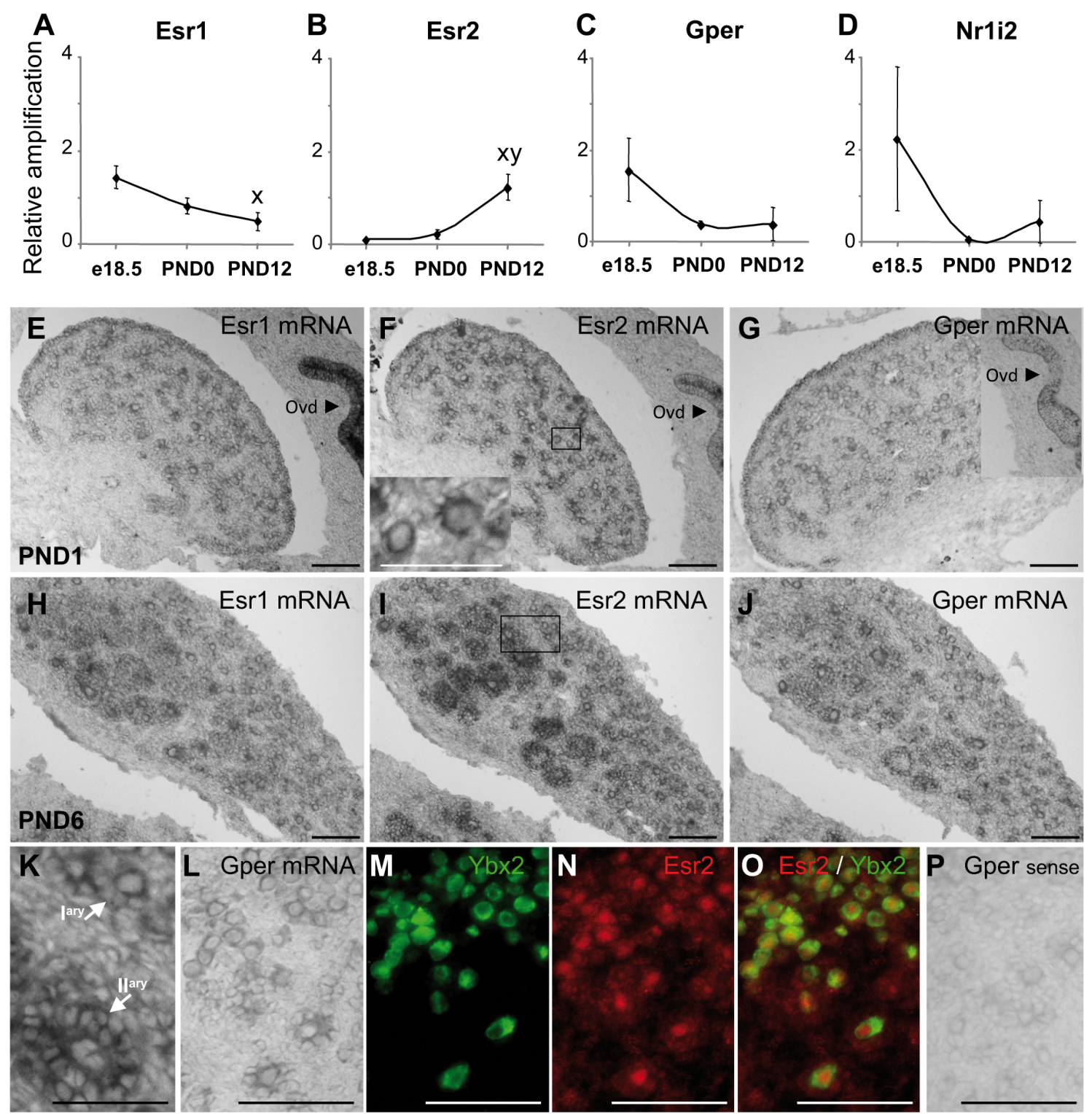

$\mathbf{N}$

Esr1

O Esr2

P Gper

Q Nr1i2
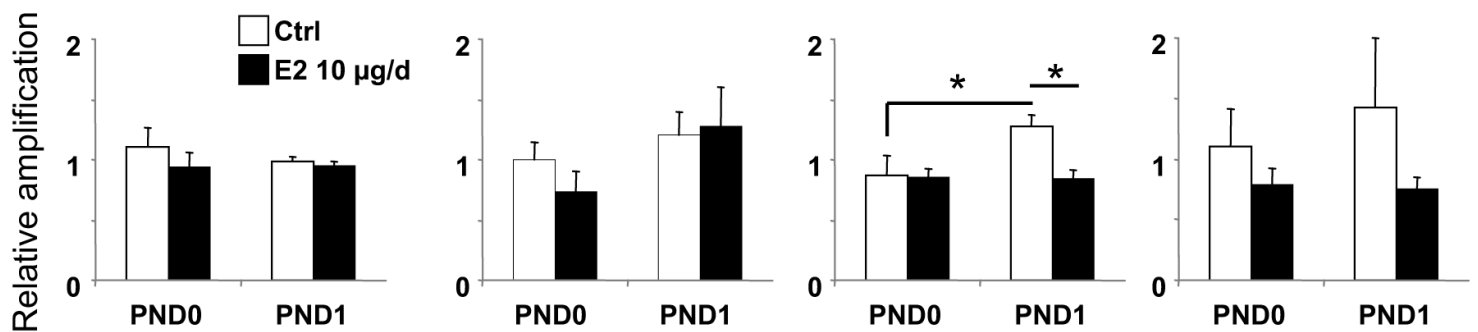

Figure 2. Perinatal ovarian receptivity to estrogens. A-D: Quantitative RT-PCR for Esr1 (A), Esr2 (B), Gper (C) and Nr1i2 (D) performed on control ovaries at e18.5, day of birth (PND0) and PND12. Each point is constituted by three pools of at least four animals. Data points represent the mean \pm SEM of the fold-change in target gene expression relative to a Snx17 reference gene and calibrator sample. Each point represents mRNA from 3 pools of ovaries from 3 animals. ${ }^{*} p<0.05$ (ANOVA, followed by PLSD test). $\mathbf{x}$ shows a statistically significant difference from e18.5 and $\mathbf{y}$ shows a statistically significant difference from PND0. E-P. In situ hybridizations for Esr1 (E, H), Esr2 (F, I, K), and Gper (G, J, L) in PND1 (E-G), PND6 (H-K) and PND2 (L-P) control ovaries show lower Esr1 expression in the ovary than in the oviduct epithelium (Ovd), higher expression of Esr2 in granulosa cells with follicle growth, and expression of Gper in the oocytes and granulosa cells. Inset in F shows a higher magnification of a group of follicles boxed in F. K shows a higher magnification of a primary (lary and a secondary (llary) follicles boxed in I. Inset in G shows another section of the ovary containing the oviduct. A comparison of Gper mRNA profile by in situ hybridization (L) with Esr2 (N, red) and Ybx2 (M, cytoplasmic, green) (and merged pictures $\mathrm{O}$ ) by immunofluorescence revealed co-expression of both receptors in oocytes at the time of treatment. $\mathrm{P}$ shows hybridization with Gper sense probe. Scale bar: $100 \mu \mathrm{m}$ except in insert in F and K (50 $\mu \mathrm{m})$. Q-T. Quantitative RT-PCR for Esr1 (Q), Esr2 (R), Gper (S) and Nr1i2 (T) using 
ovarian samples of controls (white bars) and animals treated with $10 \mu \mathrm{g} \mathrm{E2}$ at PND0 ( $2 \mathrm{~h}$ after injection) and PND1 (black bars) shows E2 impairment of post-natal Gper up-regulation. Each bar represents mean \pm SEM of the fold-change in target gene expression relative to a Snx17 reference gene and calibrator sample. Each point represents mRNAs from 3 to 6 pools of $6-16$ and $10-26$ ovaries, respectively. * $<<0.05$ (ANOVA, followed by PLSD test).

doi:10.1371/journal.pone.0082175.g002

a target of E2 in the fetal and juvenile rat ovaries [38], followed the same trend as Cyp1b1 and Cyp2b1/2, albeit not significantly (Fig. 3H).

\section{Estrogen Dose-dependent Depletion of Oocyte Pool}

Repeated $10 \mu \mathrm{g}$ E2 treatment is known to effect the volume of infantile [22] and pre-pubertal ovaries [39]. Since sections of PND3 ovaries of the $10 \mu \mathrm{g} / \mathrm{d}$ group were smallest compared to control ones at the histological level (Fig. 4A-C), we performed stereological measurements of ovarian volumes for each dose group $(10,1,0.1$ and $0.01 \mu \mathrm{g} / \mathrm{d})$ after the end of the treatment at PND3 (Fig. 4D). Ovarian volume followed a dose-dependent decrease after E2 treatment but this was only statistically significant for the $10 \mu \mathrm{g} / \mathrm{d}$ dose (Fig. 4D). Because this modification was rapid, we chose to evaluate the total number of oocytes instead of categorizing naked/primordial/primary follicles by morphological criteria using oocyte nucleus labeling with GENA [40] (Fig. 4E). Oocyte population decreased as a function of the dose of injected E2: at doses of $1 \mu \mathrm{g} / \mathrm{d}$ and above, the population size was significantly different to that of control individuals. These data suggested that neonatal E2 supplementation depletes the oocyte pool in female rats. We used the $10 \mu \mathrm{g}$ dose for further investigations as this dose had effective effects on both ovarian volume and oocyte number.

We analyzed the time-course of oocyte depletion after a $10 \mu \mathrm{g} /$ d E2 treatment (Fig. 5A). Oocyte numbers decreased with a similar slope between PND0 and PND2 in control and treated groups and oocyte depletion extended for one more day in E2-treated females (Fig. 5A). Since oocyte apoptosis is a physiological process that characterizes follicle formation [12,14], we quantified apoptotic oocytes after TUNEL assays between PND0 and PND2 in control and E2-treated females (Fig. 5B). Both groups of females displayed a similar post-natal decline in apoptotic oocyte number from PND0 to PND2 and we could not detect any difference between control and treated ovaries (Fig. 5B). In agreement, the mRNA levels of the pro-apoptotic Bax gene (measured by quantitative PCR) were stable in both control and treated ovaries between PND0 and PND2 (Fig. 5C). By contrast, the mRNA levels of the anti-apoptotic $B c l 2$ gene were steady stable in control ovaries while lower to control ones $4 \mathrm{~h}$ after the first injection and then increasing in E2-treated ovaries (Fig. 5D).

We investigated the expression of genes proposed to be involved in follicle formation (Figla, Hnrnpk, Foxo3a and Nobox) and meiosis progression (Eif4e, Scp 1) [41-47]. To detect early changes triggered by the E2 treatment, quantitative PCR were performed before a decrease in oocyte number was detected (at PND0, PND1 and PND2). E2 treatment only affected the profile of Nobox expression at PND2 (Fig. 5E-J): Nobox mRNA expression increased between PND1 and PND2 in control ovaries but not in E2-treated ones. This suggested that, apart from Nobox, genes classically involved in follicle formation may not have a role in E2-induced oocyte depletion.

\section{Abnormalities of Follicle Formation in Response to E2 Exposure}

The wave of physiological oocyte programmed cell death progresses from core areas to the periphery of the ovary in rodents [48]. Degenerating oocytes are located in areas of new basement membrane deposition which delineate the emerging follicular units [11]. We investigated the topographical pattern of oocyte degeneration by comparing TUNEL-positive cells and fibronectin-labeled extra-cellular matrix at PND1 (Fig. 6A-D). Whereas typical apoptotic oocytes were found close to basal membrane remodeling in both control and E2-treated ovaries, numerous degenerating oocytes, already enclosed in follicles, were observed in the core of the E2-treated ovaries (Fig. 6D).

Because MOFs are a hallmark of neonatal estrogenization, we investigated cord fragmentation by analyzing fibronectin-labeled basal membrane deposition around newly formed follicular units (Fig. $6 \mathrm{E}-\mathrm{H}$ ). Ovarian cord fragmentation was nearly complete in control animals at PND3 (Fig. 6E) but follicle formation anomalies, such as epithelial structures devoid of oocyte and incomplete cord fragmentation, were observed in $10 \mu \mathrm{g}$-treated animals (Fig. 6F). At PND6, an age at which follicle formation is known to be completed (Fig. 6G), many abnormalities (such as follicular units devoid of oocytes) remained in E2-treated ovaries (Fig. 6H).

\section{Discussion}

Our results provide direct evidence that the newborn female rat rapidly acquires the capability to partially protect itself against repeated E2 injections by decreasing E2 in the plasma. This is associated with a change in the expression profiles of several hepatic detoxification enzymes involved in its own metabolism. Interestingly, the ovary itself expresses enzymes for E2 metabolism and modifies their expression in response to E2. We show that neonatal E2 exposure can directly affect oocyte survival in a dosedependent manner in the rat. Oocyte depletion is time-dependent for the highest dose tested and affects already formed follicles in addition to areas of ovarian cord remodeling. The data highlights a dramatic species difference as experimentally-increased E2 levels promote oocyte survival in the mouse.

\section{Whole Organism Response to E2}

In our control female pups, E2 levels decreased from 90+/ $-3 \mathrm{pg} / \mathrm{mL}$ at PND0 to $24+/-11 \mathrm{pg} / \mathrm{mL}$ at PND3 and fell to $2+/$ $-2 \mathrm{pg} / \mathrm{mL}$ at PND6. The $0.01,0.1,1$ and $10 \mu \mathrm{g} / \mathrm{d}$ doses raised the levels up to $80+/-17,233+/-199,618+/-34$ and $3685+/$ $-968 \mathrm{pg} / \mathrm{mL}$ at PND1, respectively. By comparison, mean E2 levels in ovarian venous blood during pregnancy have been described to plateau at levels between $120+/-19$ to $199+/$ $-55 \mathrm{pg} / \mathrm{mL}$ between e3 and e17, which are close to estrus levels $(161+/-28 \mathrm{pg} / \mathrm{mL})$, then raise up to $445+/-115 \mathrm{pg} / \mathrm{mL}$ at $\mathrm{e} 21$, $348+/-74$ at e22, and peak at $628+/-210 \mathrm{pg} / \mathrm{mL}$ at parturition [49]. Studies on xeno-estrogen effects on the ovary and hypothalamus classically use a $10 \mu \mathrm{g} / \mathrm{d}$ E2 dose as a positive control $[22,27,50-54]$. By comparing the dynamics of E2 plasma levels in controls and animals treated with different doses of E2, we showed that doses from $0.1 \mu / \mathrm{d}$ tend to increase circulating E2 levels above control levels at PND1. This became statistically significant for the $10 \mu \mathrm{g} / \mathrm{d}$ dose, which raised circulating levels by up to 15 times that of the physiological levels at PND1. Thereafter, it was not possible to maintain PND0 E2 levels by E2 injection with a given dose because plasma E2 levels decreased from PND1 to PND3 despite repeated injections in the different treatment 

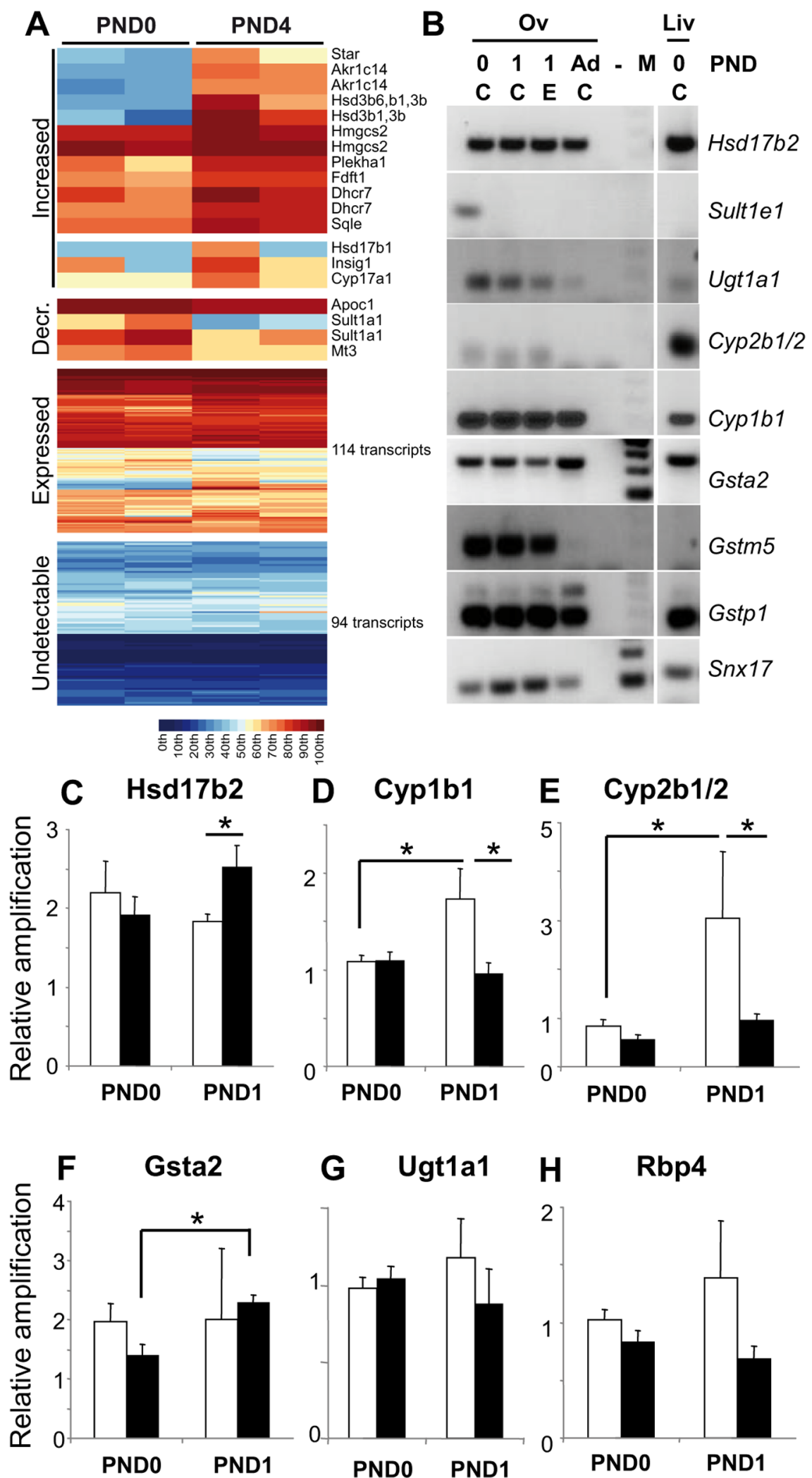

Figure 3. Ovarian reaction to acute estrogen exposure. A. A false-color heatmap shows cases of increasing, decreasing, detectable (but without differential expression) and undetectable transcript signal intensities across the replicates for different total ovary samples at the time points given (top). Each line corresponds to a probe set and each column to a sample replicate. A color scale is shown for signal intensity percentiles (bottom). Gene symbols and numbers of transcripts are shown at the right. B. Conventional RT-PCR screening of the expression of various enzymes involved in E2 metabolism in PND0, control (C) and E2-treated (E) PND1 and adult female ovaries, and PND0 livers reveals changes in expression of Ugt1a1, Gsta2, Gstm5 between newborn and adult ovaries, stable expression of Hsd17b2, Cyp1b1, Gstp1, and the faint expression of Sult1e1 and 
Cyp2b1/2 by contrast to control Snx17 RNAs. C-H. Quantitative RT-PCR for Hsd17b2 (C), Cyp1b1 (D), Cyp2b1/2 (E), Gsta2 (F), Ugt1a1 (G) and the Rbp4 E2 target gene $(\mathrm{H})$ in ovaries of controls (white bars) and animals treated with $10 \mu \mathrm{g}$ E2 (black bars) at PND0 ( $2 \mathrm{~h}$ after injection) and PND1 shows E2 impairment of post-natal Gper up-regulation. Each bar represents mean \pm SEM of the fold-change in target gene expression relative to a Snx17 reference gene and calibrator sample. Each point represents mRNAs from 3 to 6 pools of $6-16$ and $10-26$ ovaries, respectively. ${ }^{*} p<0.05$ (two-way ANOVA, followed by Tukey test).

doi:10.1371/journal.pone.0082175.g003

groups. This indicated that newborns progressively acquire the capability to clear E2 form the organism. A return to levels similar to that of controls was reached at PND6 for all dose groups but not at PND3, ie only a few days after termination of the treatment. The only dose where circulating levels were found to be higher than control levels during the whole course of the treatment was $10 \mu \mathrm{g} / \mathrm{d}$. Consequently, the effective dose at the systemic level is $10 \mu \mathrm{g} / \mathrm{d}$. In addition, although studies on neonatal estrogen exposure use either E2 or esters of E2 that display different half lives in the organism [55], the effective dose is typically $1-10 \mu \mathrm{g} / \mathrm{d}$ at the hypothalamus level [22,27,50-54]. By addressing dose effects, we show here that a $10 \mu \mathrm{g} / \mathrm{d}$ is also the effective dose in the ovary.

Altogether, our results on hormone profiling and mRNA quantification after E2 injections suggest that the newborn rat acquires the complex capability to metabolize E2 according to fine dynamics in the days following birth. Estradiol metabolism is carried out by enzymes that convert E2 to a biologically less active estrogen (E1) and by phase-I and II enzymes that catalyze oxidation and conjugations to permit their rapid excretion by the kidney (Fig. 1A). The decrease of circulating E2 in controls suggests that mother-derived E2 is cleared by the newborn, insofar as the newborn itself does not synthesize E2. At birth, the rat ovary is not able to produce E2 [56] until the granulosa cells of the first wave of follicular growth typically express Cyp19a1. This typical expression is associated with the peak levels of E2 during the infantile period [5,6]. By PND2, even after repeated injections of the highest dose, circulating E2 levels decreased concomitantly with a sharp increase of E1. This suggests that newborn females can convert excessive E2 into E1, which is supported by Hsd17b2 activity. Subsequent conversion of E2 and E1 into hydroxylmetabolites is handled by typical phase I enzymes of the Cyp family, ie Cypla2, 2bl/2, 2c6, 2c11 and the 3a family [57-59]. Phase II estrogen metabolism includes sulfatation, glucuronidation, $O$-methylation and glutathione-conjugation, which are catalyzed by sulfo- (Sult), UDP-glucuronosyl- (Ugt), catechol-Omethyl- (COMT) and Glutathion-S-Transferases (Gst), respectively. Sulfates and glucuronides are the most abundant circulating estrogen conjugates [60]. While glucuronides are primarily excretion forms, sulfate derivatives have also been described as storage forms [60,61]. The absence of statistical changes in circulating levels of sulfated estrogens, excepted for E1S at PND3, could reflect either the absence of increased sulfatation process (and possibly the absence of regulation of expression and/or activity of enzymes in charge of this process), or an increase of the excretion of sulfate-conjugated estrogens, or both.

We were not able to measure the hydroxyl- and glucuronideconjugated metabolites of E2 and E1 because of their instability and the low quantity of plasma that can be recovered in each newborn. We therefore investigated hepatic regulation of the mRNA expression of selected relevant enzymes of the E2 metabolic pathway. In agreement with the well-known post-natal
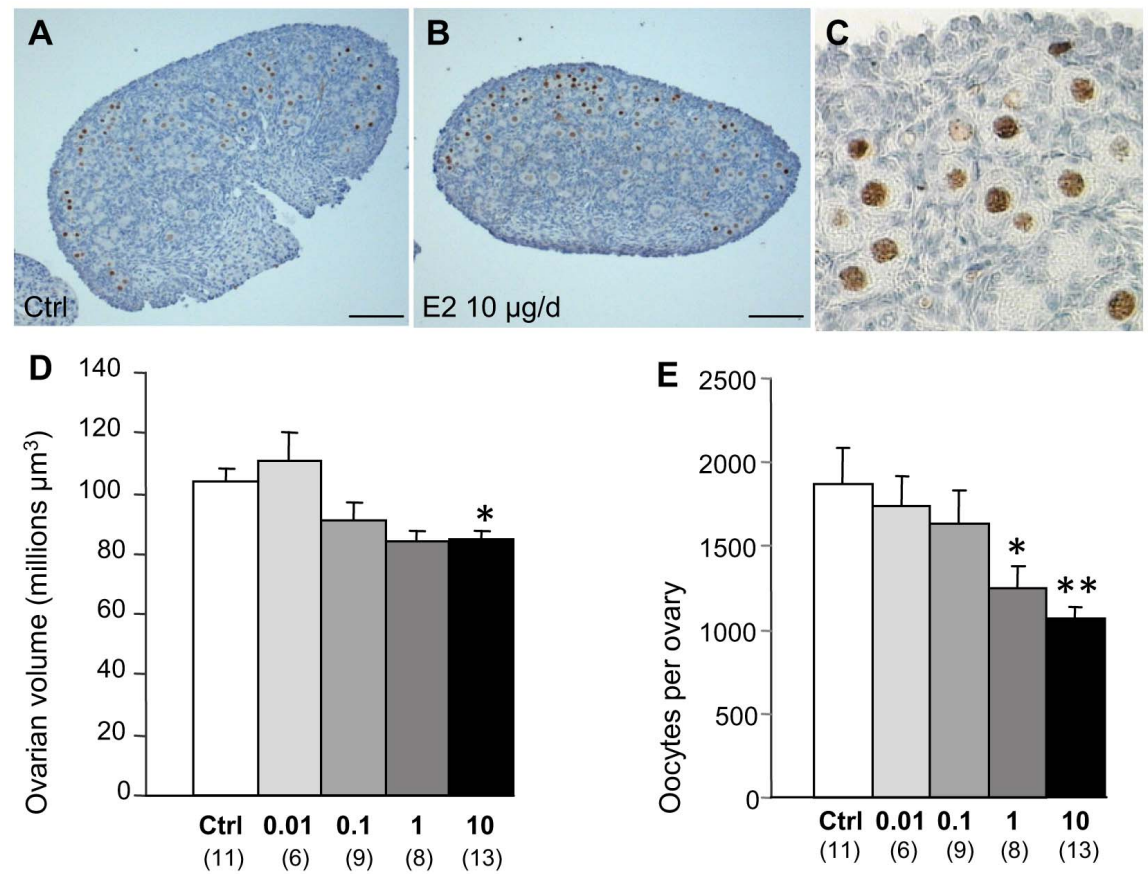

Figure 4. Estrogen dose-dependent depletion of oocytes. A-C. Immunolabeling of TRA98 in oocytes of control animals at PND3 (A) and females treated daily with $10 \mu \mathrm{g} / \mathrm{d}$ E2 between PND0 and PND2 (B). Higher magnification of TRA98 labeling shows oocyte-specific expression (C). Scale bar $=100 \mu \mathrm{m}$. D-E. Stereological estimation of ovarian volume (D) and oocyte numbers per ovary (E) at PND3 in controls, and as a function of E2 dose, show a dose-dependent decrease of both parameters. Each bar represents means \pm SEM. Number of ovaries are indicated in brackets on the abscissa. ${ }^{*} p<0.01 ;{ }^{* *} p<0.001$ (ANOVA followed by Fisher test).

doi:10.1371/journal.pone.0082175.g004 

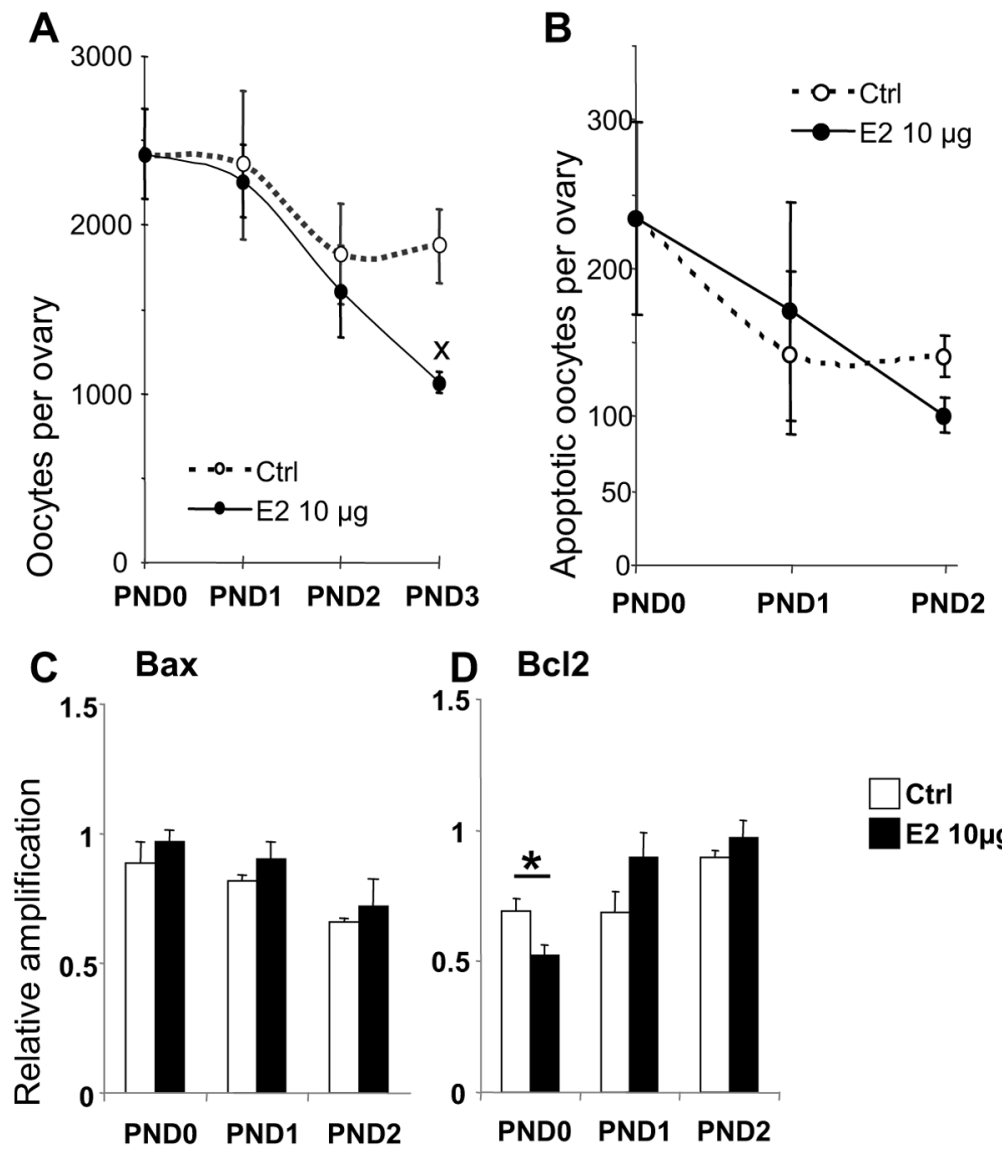

D Bcl2
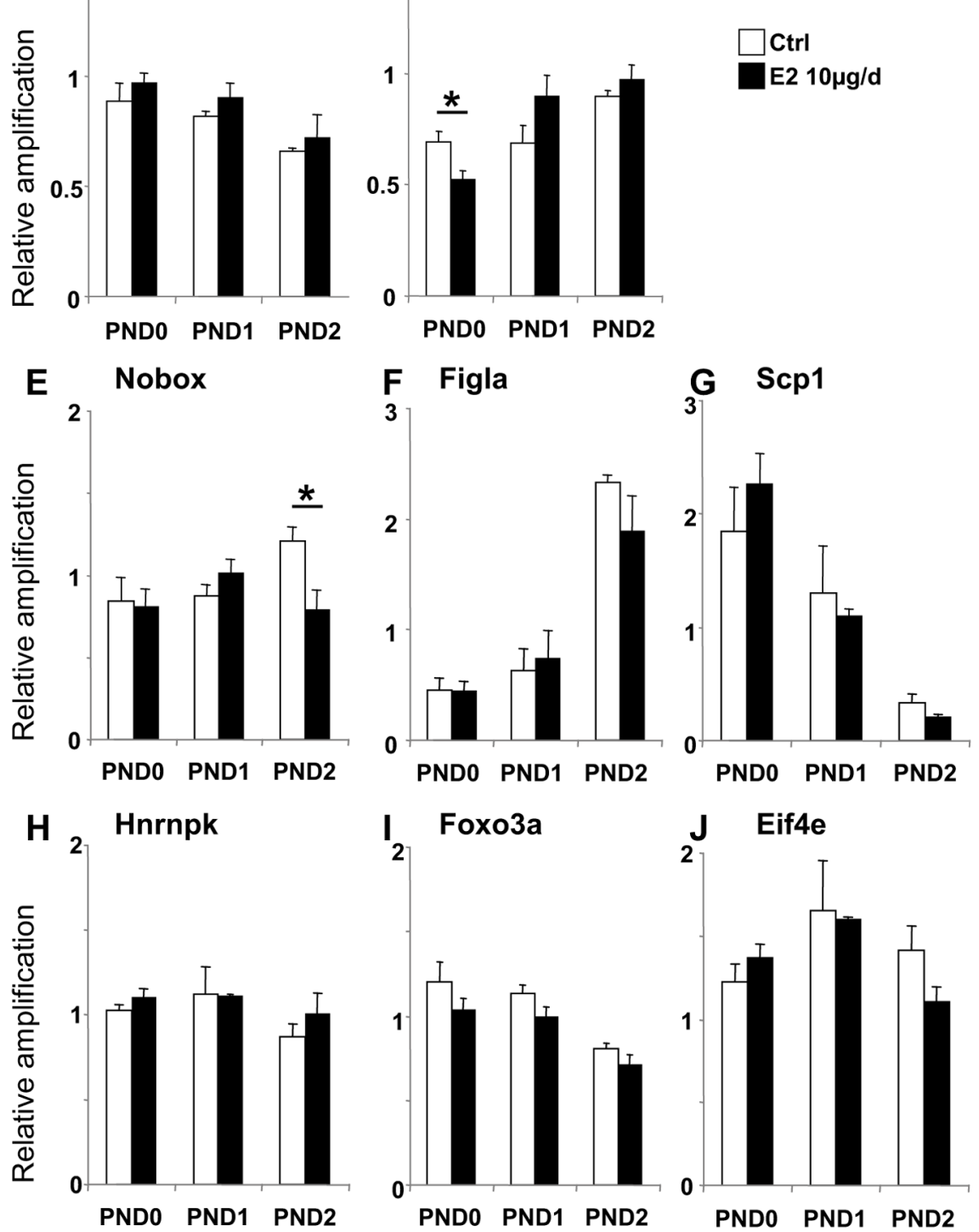

Figure 5. Characterization of oocyte depletion. A. Time-course showing the decline in oocyte number per ovary in control (white points and dotted lines) and $10 \mu \mathrm{g}$ E2-treated ovaries (black points and continuous lines) from PND0 to PND3. Data are expressed as mean \pm SEM of 5-14 ovaries. ${ }^{*} p<0.01$ vs. age-matched controls (ANOVA followed by PLSD test). B. Time-course of apoptotic oocyte number per ovary in control (white 
points and dotted lines) and $10 \mu \mathrm{g}$ E2-treated ovaries (black points and continuous lines) from PND0 to PND2. Data are expressed as mean \pm SEM of 4-8 ovaries. C-D. Quantitative RT-PCR for Bax (C), BCl2 (D), Nobox (E), Figla (F), Scp1 (G), Hnrnpk (H), Foxo3a (I) and Eif4e (J) in ovarian samples of controls (white bars) and animals treated with $10 \mu \mathrm{g} \mathrm{E2} \mathrm{(black} \mathrm{bars)} \mathrm{at} \mathrm{PND0} \mathrm{(2} \mathrm{h} \mathrm{after} \mathrm{injection)} \mathrm{and} \mathrm{PND1} \mathrm{shows} \mathrm{transient} \mathrm{down-regulation} \mathrm{of} \mathrm{Bc/2}$ mRNA at PND0 and the absence of Nobox mRNA up-regulation between PND1 and PND2 in E2-treated ovaries. Each bar represents mean \pm SEM of the fold-change in target gene expression relative to a Snx17 reference gene and calibrator sample). Data from 3-6 pools of 6-14 ovaries. ${ }^{*} \mathrm{p}<0.05 \mathrm{vs}$. age-matched control (two-way ANOVA, followed by t-test). doi:10.1371/journal.pone.0082175.g005

maturation of the hepatic endowment of enzymes of lipid metabolism [7,62,63], we found up-regulation of $H s d 17 b 2$, Cyp2b1/2 and Gsta2 and down-regulation of Cyp1b1 mRNA levels between PND0 and 1. In contrast, transcripts encoding Ugtlal (which contribute to glucuronide conjugation together with Ugtla3, la8, la9, 1a10 and $2 \mathrm{~b} 7[64,65,66])$, were not modified between PND0 and PND1. Despite its major protecting role against $\mathrm{E} 2$ effects in male tissues, and the clear reproductive phenotype in females lacking its expression $[67,68]$, it was not possible to investigate Sultlel regulation of expression as it was expressed at levels below the qPCR threshold.

Our mRNA quantifications in the liver suggest that E2 itself, at least at the highest dose, inhibited the physiological up-regulation of hepatic $H s d 17 b 2$ and $C y p 2 b 1 / 2$ mRNA, which encode two key enzymes of the E2 detoxification pathway. This could indicate that the level of enzymes in the newborn liver is sufficient for E2 conversion. Alternatively, E2 treatment could counter the physiological acquisition of the newborn liver to convert E2 into less active metabolites. By contrast, E2 treatment had no effect on physiological neonatal Cyp1b1 down-regulation and Gsta2 upregulation of expression in the liver. Cyplbl response to E2 exposure seems to be organ-specific since its expression is either inducible by E2 and deoxymiroestrol (a strong phyto-estrogen in mouse hepatocyte primary culture [69]) or down-regulated by estrogenic compounds in peripheral organs such as rat and mouse testis and the reproductive tract of developing female rats $[38,70,71]$. This may also be the case for Gst enzymes as genistein increases Gsta2 mRNA levels and decreases Gstpl mRNA levels without affecting general GST activity in adult males, and deoxymiroestrol increases Gsta2 expression in adult mice hepatocyte primary culture [69,72]. Finally, hepatic Ugt1a1 mRNA levels were not modified by E2. This would suggest that E2 treatment has no influence on the expression of this enzyme at this age, unlike in adult mouse livers where its expression is inducible [73]. Nevertheless, the absence of effect of E2 on Ugt1a1 and Gsta2 mRNA neonatal profiles does not preclude a modification of expression of other Gst and Ugt, or a modification of enzyme activity. By targeting selected enzymes of the metabolizing pathway, E2 treatment may well favor one or more metabolic branches over others. Collectively, our data led us to hypothesize that by reproducing the maternal E2 environment, high levels of E2 levels would force the liver to remain in a relative immature state. Therefore, as suggested in the ovary, lifting the maternal E2 environment at birth could enable maturation of the newborn liver and development of its own detoxification machinery.

\section{Arguments in Favor of the Existence of an Ovarian Local Metabolic Response to E2 Exposure}

Neonatal estrogen exposure classically induce immediate transcriptomic effects and long-lasting physio-pathological effects in reproductive tissues such as the testis, ovary, uterus, oviduct and hypothalamus, but also in other tissues including bone, kidney and liver [74]. The search of E2 target genes is the main outcome that is commonly investigated at the transcriptomic level. Amongst target genes, E2 induces modifications of the detoxification machinery in the rat adult female liver, which is the major drug- metabolizing organ of the body [75,76], but also in reproductive organs such as uterus, testis and fetal and juvenile ovaries $[38,77,78]$. In agreement, our results suggest that local mechanisms may exist in the neonatal ovary as well. Indeed, the ovary responds to E2 exposure by modifying the expression of several E2 metabolism pathway enzymes. Although $H s d 17 b 2$ mRNA was not thought to be expressed in the immature and mature rat ovary [79], we found an up-regulation above basal levels in response to a $10 \mu \mathrm{g}$ E2 injection that may increase the capability of the ovary to transform E2 into its less active E1 metabolite [80]. On the opposite, the PND0 to PND1 up-regulation of Cyp1b1 and Cyp2b1/2 mRNA levels was not observed in response to a $10 \mu \mathrm{g}$ E2 injection, suggesting a possible decreased capability to locally transform circulating E2 and E1 into excretable hydroxyl- and methoxy-estrogen metabolites. We propose that, as in the liver, E2 treatment could also counter local ovarian acquisition of the machinery involved in its own metabolism, as illustrated by a similar inhibition of post-natal Cyp2b1/2 mRNA up-regulation. The local ovarian mRNA up-regulation of $H s d 17 b 2$ may locally rescue, at least in part, the absence of up-regulation in the liver.

An auto-sensory mechanism adjusting the expression of detoxification enzymes would involve local signaling via estrogen receptors. In agreement with previous reports in the rat [81,82], we confirm lower expression of Esrl in the neonatal rat ovary than in the oviduct, expression of Esr2 in (pre-)granulosa cells which increases with follicular growth, and low expression of Esr2 in the cytoplasm of oocytes at birth. We also extend the knowledge of Gper expression pattern in the rat to the neonatal period in granulosa cells, oocytes, and surface epithelial cells of the ovary and the oviduct, consistent with the pattern reported in the hamster $[19,83]$. Altogether, the neonatal rat ovary has the machinery to respond to E2. In contrast to other organs or developmental periods, we were not able to show any modification of either Esr1 or Esr2 expression associated with the $10 \mu \mathrm{g} / \mathrm{d}$ E2 treatment. Gper mRNA, which has not been described as a classical E2 target gene to our knowledge, did not display a physiological increase between PND0 and PND1 in response to E2. In the hamster, Gper was proposed to mediate E2 action on follicle formation, as in vitro ablation with small interfering RNAs markedly suppressed estrogen-stimulated primordial follicle formation [19]. E2-disruption of post-natal Gper increase may suggest a similar role of Gper in follicle formation in the rat. The same trend of response to E2, albeit not statistically significant, was found for $\mathrm{Nr} 1 \mathrm{i} 2$ expression in agreement with mouse ovarian data). Interestingly, the sharp increase in $\mathcal{N r} 1 i 2$ expression in the prenatal mouse ovary followed by a post-natal decrease at PND3, that we also found in the rat ovary, was proposed to reflect a role for this receptor in protecting the feto-maternal system from the toxic effect of endogenous steroids and foreign substrates [36]. Unfortunately, Nr1i2 mRNA levels were below our in situ hybridization detection levels so we were unable to identify the cells that express Nr1i2. The low expression level of Nrli2, together with the absence of modification to its expression by E2, reduces the likelihood of its involvement in the response to E2 high levels. 

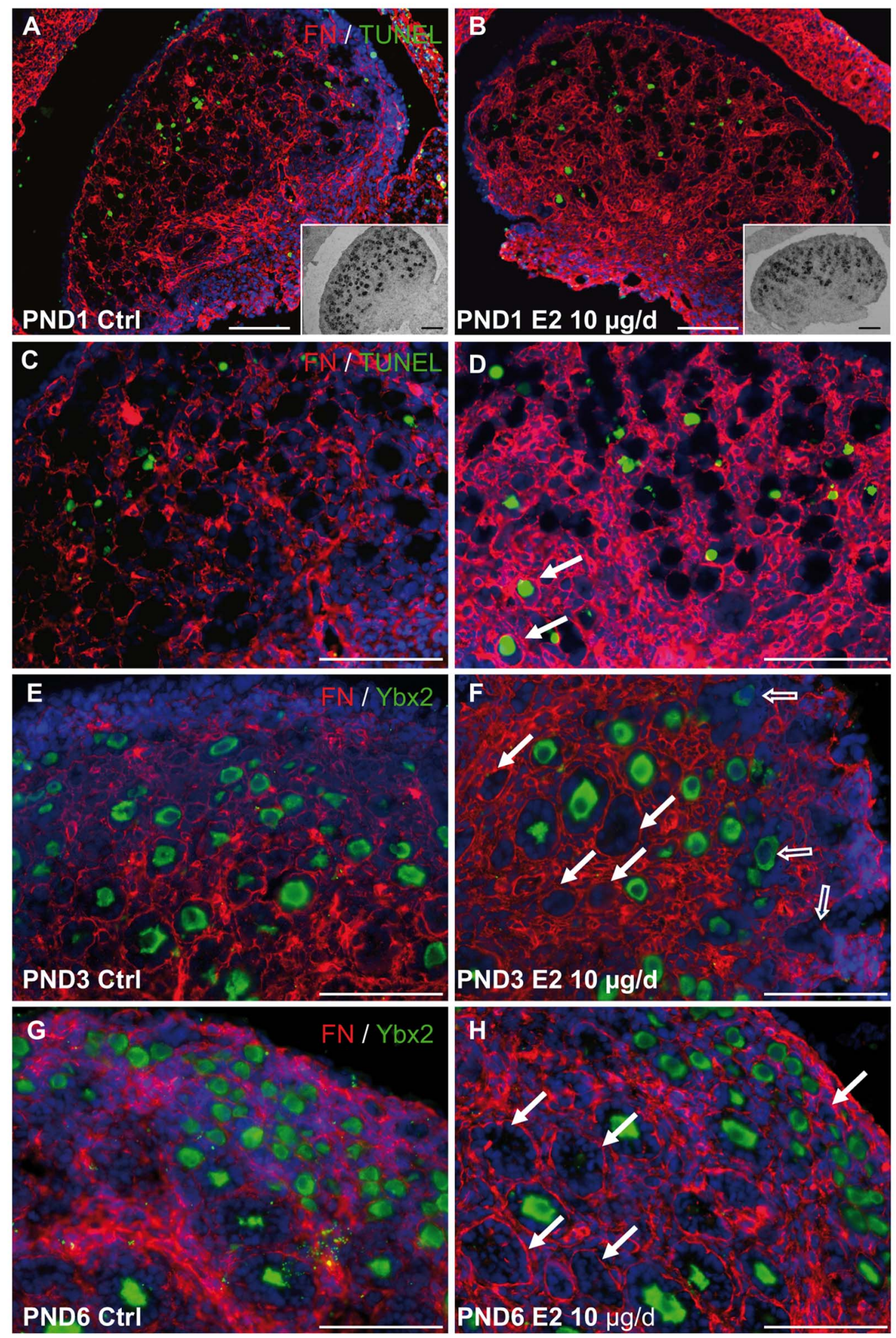

Figure 6. Abnormalities of follicle formation. A-D. Comparison of apoptosis using TUNEL (green), fibronectin (red) and nuclei (DAPI, blue) in control (A, C) or $10 \mu \mathrm{g}$-E2 treated (B, D) ovaries at PND1 highlights physiological oocyte apoptosis in the areas of ovarian cords remodeling in control ovaries, and additional oocyte apoptosis in already formed follicles in E2-treated ovaries (arrows). Insets in A-B show in situ hybridization against Ybx2 performed on the same section. C-D are higher magnifications of A-B. Scale bar: $100 \mu \mathrm{m}$. E-H. Comparison of oocytes labeled with Ybx2 (green) and basement membrane labeled with fibronectin (red) and nuclei (DAPI, blue) in PND3 (E-F) and PND6 (G-H) control (E, G) and $10 \mu \mathrm{g}$ E2-treated ovaries $(\mathrm{F}, \mathrm{H})$ show incomplete basement membrane remodeling at PND3 in E2-treated ovaries (open arrows) and empty follicles at PND3 and PND6 (arrows). Pictures are representative from 4-6 ovaries. Scale bar: $100 \mu \mathrm{m}$. doi:10.1371/journal.pone.0082175.g006 


\section{Estradiol and Oocyte Survival}

Although the $10 \mu \mathrm{g} / \mathrm{d}$ E2 treatment induced a local modification in the expression of genes encoding metabolism enzymes, we showed that E2 exposure at the time of follicle formation induced a dose-dependent ovotoxicity. The effect of E2 on the neonatal ovary is often evaluated at the follicle level and previous studies have shown that neonatal E2 exposure induces a moderate reduction in the rate of primordial follicle assembly, a lower level of initial primordial-to-primary follicle transition [16] and fewer layered follicles at PND6 [84]. Similarly, neonatal exposure to BPA reduces the pool of primordial follicles in the rat ovary [28]. Nevertheless, there may be multiple effects of E2 on follicle assembly and/or primordial follicle activation. By focusing on the total oocyte number, we showed a rapid effect of E2 on oocyte survival, irrespective of the structure in which it is included. Further studies are necessary to identify the fine mechanisms by which E2 affects oocyte survival. However, our results contrast with those reported in mice in which a similar range of EB doses ( 0.1 to $1 \mu \mathrm{g} /$ mouse) decrease the number of apoptotic germ cells at PND5 [85-87]. In other in vivo studies in mice, 10 or $20 \mu \mathrm{g} /$ day of ethinyl estradiol did not modify whereas $100 \mu \mathrm{g} /$ day increased the number of oocyte per section [18,88,89], highlighting the importance of the dose. In agreement, studies in hamsters revealed that doses of $\mathrm{E} 2$ within the physiological range reduced apoptosis and stimulated the formation of follicles, and that doses above a threshold level had no effect on primordial follicle formation but significantly up-regulated oocyte apoptosis [20]. We show a dose-effect of E2 on oocyte depletion in the rat but no biphasic response.

There may be several reasons for species-differences in ovarian E2 sensitivity. Distinct estrogen receptivity at the time of follicle assembly are unlikely because of the highly conserved expression profiles of the different estrogen receptors, especially between these rodent species $[82,83,90]$. Subtle species differences between rat and mice have been reported in the fine mechanisms governing the programmed cell death of oocytes at birth. Neonatal oocyte attrition in mice involves apoptosis and autophagy mechanisms in different cells [91], but in rats, dying oocytes can share several features of both processes [14]. Alternatively, the xeno-estrogen Bisphenol A was shown to hamper meiotic progression, resulting in oocyte apoptosis in mice and humans $[92,93]$. This indicates that E2 could interfere with the timing of meiosis arrest during follicle histogenesis and ultimately induce oocyte death. Our search for meiosis or oocyte-specific marker profiles in response to E2 treatment showed that only Nobox expression was modified in ovaries of E2-treated females. Indeed, Nobox mRNA did not display the up-regulation observed between PND0-1 and PND2 in control ovaries. This increase in controls may reflect the expression of Nobox in oocytes of primordial and growing follicles and thus the maturation of the organ. In E2-treated ovaries, the absence of increased Nobox expression between PND1 and PND2 could indicate a default in the primordial-to-primary follicle transition or a poor growth of the first wave of follicles. However, this is countered by the absence of modification of expression in several other oocyte-specific genes. Since mice lacking Nobox display accelerated post-natal oocyte loss associated with a decrease in the expression of numerous oocyte-specific genes [44,94], the absence of increase of Nobox could involve this pathway in the mechanism by which oocytes disappear after E2 exposure. This alternative mechanism would correlate well with the delayed decrease in oocyte numbers between PND2 and PND3. Nevertheless, although we were not able to detect any changes of the number of TUNEL-positive apoptotic oocytes, or global expression of apoptosis-related genes, we showed difference in areas and structures where apoptotic oocytes were included. This would suggest that E2 induces abnormal apoptosis in already formed follicles rather than increasing physiological process. Abnormal apoptosis of oocytes in already formed follicles correlates well with the observation of numerous empty follicles at PND3 and PND6. At the organ level, the number of oocytes involved in cell death is very low; this would explain the absence of variation of several selected oocyte markers. Further work is needed to define the fine mechanisms of oocyte disappearance after E2 exposure.

\section{Estradiol and Abnormalities of Follicle Formation?}

MOFs are a hallmark of several mammalian species but their etiology is unknown [95]. Studies using E2 and E2-mimetics in mice suggest that a decrease in oocyte apoptosis and cyst breakdown ultimately results in MOFs $[18,86]$. By contrast in the rat, massive oocyte depletion following fetal irradiation is associated with an increased incidence of MOFs [96]. Consequently, the etiology of MOFs in rat and mouse may well differ. We show here that E2 exposure is associated with neonatal oocyte depletion but we did not observe MOFs in older ovaries (at PND6, PND21 and in adults, data not shown). This is in agreement with studies in rats exposed to DES and BPA where MOFs were not reported, or disappeared before puberty $[27,28,51,84]$. The timing of oocyte depletion, between PND2 and PND3 and the presence of apoptotic oocytes in already formed follicles at PND1 suggest that the absence of MOFs may be explained by a depletion of oocytes after follicle formation.

It is well established that the moment of germ cell depletion will determine the subsequent ovarian phenotype. Irradiation-induced fetal depletion of germ cells in the rat results in streak gonads, whereas PND5-oocyte depletion leads to empty-primary follicles evolving into cord-like structures where granulosa cells transdifferentiate into Sertoli-like cells [97-99]. Neonatal exposure to E2 in the ovaries leads to a phenotype that is more closely related with neonatal irradiation, with a decreased oocyte pool. We here show that neonatal E2 exposure induced oocyte depletion in already formed follicles. Although further investigations on the fate of pathological empty follicles are needed, we cannot exclude the possibility that neonatal E2 exposure may also target the first wave of follicle growth and follicle dynamics at the end of the first week. Indeed, studies focusing on follicle dynamics in infantile rat ovaries after neonatal E2 exposure have produced contradictory results: some indicate that E2 increases primordial-to-primary follicle transition in vitro and in vivo at PND8 while others report a decrease in the number of layered follicles at PND6 [16,28,84]. However, by focusing on total oocyte numbers, our study shows that E2 affected oocyte survival independently of the structure in which oocytes are enclosed, in addition to its possible impact on follicle dynamics.

Our study shows that a neonatal exposure to high E2 levels interferes with the maturation of expression of key detoxification tools in the liver and ovaries. In the rat ovary, E2 is ovotoxic in a dose-dependent manner. A special care must be taken when assigning the E2 reference dose in future studies to enable accurate comparisons with environmental contaminants displaying estrogenic activities.

\section{Supporting Information}

Figure S1 Expression of Esr1 in the neonatal rat ovary. A-F. In situ hybridizations for Esr l (A, C, E), and Esr l sense probe $(\mathrm{B}, \mathrm{D}, \mathrm{F})$ in PND2 ovaries show a high level of expression of Esr 1 in the epithelium of the differentiating oviduct (compare $\mathrm{G}$ to $\mathrm{D}$ ), 
and in some cells of the mesenchyme of the oviduct (open arrow in C) and a close-to-background expression in oocytes (arrows in E, compare to $\mathrm{F}$ ) and an expression in the ovarian surface epithelium (E, compare with F). G Double staining of $\mathrm{E}$ with $\mathrm{Ybx} 2$ by immunofluorescence to labeled oocytes (arrows, red). Nuclei are counterstained with DAPI (blue). H Merged pictures of immunofluorescence for Esr1 (red), Ybx2 (green) and cell nuclei (blue) in a PNDl ovary shows a high expression of Esrl in cells of the oviduct mesenchyme (open arrow), an expression in epithelial cells of the ovarian surface and follicles (arrowheads) and in oocytes (arrow). Scale bars: $100 \mu \mathrm{m}$.

(TIF)

Table S1 GC-MS serum analytical control validation. LLOQ: low limit of quantification; QC: quality control.

\section{References}

1. Montano MM, Welshons WV, vom Saal FS (1995) Free estradiol in serum and brain uptake of estradiol during fetal and neonatal sexual differentiation in female rats. Biol Reprod 53: 1198-1207.

2. Weisz J, Ward IL (1980) Plasma testosterone and progesterone titers of pregnant rats, their male and female fetuses, and neonatal offspring. Endocrinology 106 : 306-316.

3. Konkle AT, McCarthy MM (2011) Developmental time course of estradiol, testosterone, and dihydrotestosterone levels in discrete regions of male and female rat brain. Endocrinology 152: 223-235.

4. Lei L, Jin S, Mayo KE, Woodruff TK (2010) The interactions between the stimulatory effect of follicle-stimulating hormone and the inhibitory effect of estrogen on mouse primordial folliculogenesis. Biol Reprod 82: 13-22.

5. Mazaud S, Guigon CJ, Lozach A, Coudouel N, Forest MG, et al. (2002) Establishment of the reproductive function and transient fertility of female rats lacking primordial follicle stock after fetal gamma-irradiation. Endocrinology 143: 4775-4787

6. Meijs-Roelofs HM, Uilenbroek JT, de Jong FH, Welschen R (1973) Plasma oestradiol-17beta and its relationship to serum follicle-stimulating hormone in immature female rats. J Endocrinol 59: 295-304.

7. de Zwart L, Scholten M, Monbaliu JG, Annaert PP, Van Houdt JM, et al. (2008) The ontogeny of drug metabolizing enzymes and transporters in the rat. Reprod Toxicol 26: 220-230.

8. Lee JS, Ward WO, Liu J, Ren H, Vallanat B, et al. (2011) Hepatic xenobiotic metabolizing enzyme and transporter gene expression through the life stages of the mouse. PLoS One 6: e24381.

9. Hirshfield AN (1991) Development of follicles in the mammalian ovary. Int Rev Cytol 124: 43-101.

10. Pepling ME (2012) Follicular assembly: mechanisms of action. Reproduction 143: 139-149.

11. Mazaud S, Guyot R, Guigon CJ, Coudouel N, Le Magueresse-Battistoni B, et al. (2005) Basal membrane remodeling during follicle histogenesis in the rat ovary: contribution of proteinases of the MMP and PA families. Dev Biol 277: 403416.

12. Beaumont HM, Mandl AM (1962) A quantitative and cytological study of oogonia and oocytes in the foetal and neonatal RAT. Proc R Soc Lond B Biol Sci 155: 557-579.

13. Burgoyne PS, Baker TG (1985) Perinatal oocyte loss in XO mice and its implications for the aetiology of gonadal dysgenesis in XO women. J Reprod Fertil 75: 633-645.

14. Escobar ML, Echeverria OM, Ortiz R, Vazquez-Nin GH (2008) Combined apoptosis and autophagy, the process that eliminates the oocytes of atretic follicles in immature rats. Apoptosis 13: 1253-1266.

15. Ghafari F, Gutierrez CG, Hartshorne GM (2007) Apoptosis in mouse fetal and neonatal oocytes during meiotic prophase one. BMC Dev Biol 7: 87.

16. Kezele P, Skinner MK (2003) Regulation of ovarian primordial follicle assembly and development by estrogen and progesterone: endocrine model of follicle assembly. Endocrinology 144: 3329-3337.

17. Nilsson EE, Skinner MK (2009) Progesterone regulation of primordial follicle assembly in bovine fetal ovaries. Mol Cell Endocrinol 313: 9-16.

18. Chen Y, Jefferson WN, Newbold RR, Padilla-Banks E, Pepling ME (2007) Estradiol, progesterone, and genistein inhibit oocyte nest breakdown and primordial follicle assembly in the neonatal mouse ovary in vitro and in vivo. Endocrinology 148: 3580-3590.

19. Wang C, Prossnitz ER, Roy SK (2008) G protein-coupled receptor 30 expression is required for estrogen stimulation of primordial follicle formation in the hamster ovary. Endocrinology 149: 4452-4461.

20. Wang C, Roy SK (2007) Development of primordial follicles in the hamster: role of estradiol-17beta. Endocrinology 148: 1707-1716.

21. Zachos NC, Billiar RB, Albrecht ED, Pepe GJ (2002) Developmental regulation of baboon fetal ovarian maturation by estrogen. Biol Reprod 67: 1148-1156.

22. Ikeda Y, Nagai A, Ikeda MA, Hayashi S (2001) Neonatal estrogen exposure inhibits steroidogenesis in the developing rat ovary. Dev Dyn 221: 443-453.
(DOG)

\section{Acknowledgments}

The authors thank Dr. Solange Magre for her critical reading of the manuscript and productive discussions. We also thank Dr. Nathalie Dejucq-Rainsford for critical discussions about the direction of this study.

\section{Author Contributions}

Conceived and designed the experiments: CG FG JF BJ SMG. Performed the experiments: CG FG SMG. Analyzed the data: CG FG FG SMG. Contributed reagents/materials/analysis tools: FG JF. Wrote the paper: CG FG FG SMG.

23. Iguchi T, Fukazawa Y, Uesugi Y, Takasugi N (1990) Polyovular follicles in mouse ovaries exposed neonatally to diethylstilbestrol in vivo and in vitro. Biol Reprod 43: 478-484.

24. Iguchi T, Kamiya K, Uesugi Y, Sayama K, Takasugi N (1991) In vitro fertilization of oocytes from polyovular follicles in mouse ovaries exposed neonatally to diethylstilbestrol. In Vivo 5: 359-363.

25. Jefferson W, Newbold R, Padilla-Banks E, Pepling M (2006) Neonatal genistein treatment alters ovarian differentiation in the mouse: inhibition of oocyte nest breakdown and increased oocyte survival. Biol Reprod 74: 161-168.

26. Suzuki A, Sugihara A, Uchida K, Sato T, Ohta Y, et al. (2002) Developmental effects of perinatal exposure to bisphenol-A and diethylstilbestrol on reproductive organs in female mice. Reprod Toxicol 16: 107-116.

27. Losa SM, Todd KL, Sullivan AW, Cao J, Mickens JA, et al. (2011) Neonatal exposure to genistein adversely impacts the ontogeny of hypothalamic kisspeptin signaling pathways and ovarian development in the peripubertal female rat. Reprod Toxicol 31: 280-289.

28. Rodriguez HA, Santambrosio N, Santamaria CG, Munoz-de-Toro M, Luque EH (2010) Neonatal exposure to bisphenol A reduces the pool of primordial follicles in the rat ovary. Reprod Toxicol 30: 550-557.

29. Bateman HL, Patisaul HB (2008) Disrupted female reproductive physiology following neonatal exposure to phytoestrogens or estrogen specific ligands is associated with decreased GnRH activation and kisspeptin fiber density in the hypothalamus. Neurotoxicology 29: 988-997.

30. Navarro VM, Castellano JM, Fernandez-Fernandez R, Barreiro ML, Roa J, et al. (2004) Developmental and hormonally regulated messenger ribonucleic acid expression of KiSS-1 and its putative receptor, GPR54, in rat hypothalamus and potent luteinizing hormone-releasing activity of KiSS-1 peptide. Endocrinology 145: 4565-4574.

31. Giton F, Fiet J, Cornu JN, Cussenot O, Belanger A, et al. (2011) Serum sex steroids measured in middle-aged European and African-Caribbean men by gas chromatography-mass spectrometry. Eur J Endocrinol 165: 917-924.

32. Labrie F, Belanger A, Belanger P, Berube R, Martel C, et al. (2007) Metabolism of DHEA in postmenopausal women following percutaneous administration. J Steroid Biochem Mol Biol 103: 178-188.

33. Giton F, Caron P, Berube R, Belanger A, Barbier O, et al. (2010) Plasma estrone sulfate assay in men: Comparison of radioimmunoassay, mass spectrometry coupled to gas chromatography (GC-MS), and liquid chromatography-tandem mass spectrometry (LC-MS/MS). Clin Chim Acta 411: 1208-1213.

34. Kezele PR, Ague JM, Nilsson E, Skinner MK (2005) Alterations in the ovarian transcriptome during primordial follicle assembly and development. Biol Reprod 72: 241-255.

35. Chalmel F, Primig M (2008) The Annotation, Mapping, Expression and Network (AMEN) suite of tools for molecular systems biology. BMC Bioinformatics 9: 86.

36. Masuyama H, Hiramatsu Y, Mizutani Y, Inoshita H, Kudo T (2001) The expression of pregnane $\mathrm{X}$ receptor and its target gene, cytochrome $\mathrm{P} 450$ 3A1, in perinatal mouse. Mol Cell Endocrinol 172: 47-56.

37. Mnif W, Pascussi JM, Pillon A, Escande A, Bartegi A, et al. (2007) Estrogens and antiestrogens activate hPXR. Toxicol Lett 170: 19-29.

38. Daston GP, Naciff JM (2005) Gene expression changes related to growth and differentiation in the fetal and juvenile reproductive system of the female rat: evaluation of microarray results. Reprod Toxicol 19: 381-394.

39. Adewale HB, Jefferson WN, Newbold RR, Patisaul HB (2009) Neonatal bisphenol-a exposure alters rat reproductive development and ovarian morphology without impairing activation of gonadotropin-releasing hormone neurons. Biol Reprod 81: 690-699.

40. Tanaka H, Pereira LA, Nozaki M, Tsuchida J, Sawada K, et al. (1997) A germ cell-specific nuclear antigen recognized by a monoclonal antibody raised against mouse testicular germ cells. Int J Androl 20: 361-366.

41. Lechowska A, Bilinski S, Choi Y, Shin Y, Kloc M, et al. (2011) Premature ovarian failure in nobox-deficient mice is caused by defects in somatic cell invasion and germ cell cyst breakdown. J Assist Reprod Genet 28: 583-589. 
42. Miyagi Y, Kerr S, Sugiyama A, Asai A, Shibuya M, et al. (1995) Abundant expression of translation initiation factor EIF-4E in post-meiotic germ cells of the rat testis. Lab Invest 73: 890-898.

43. Paredes A, Garcia-Rudaz C, Kerr B, Tapia V, Dissen GA, et al. (2005) Loss of synaptonemal complex protein-1, a synaptonemal complex protein, contributes to the initiation of follicular assembly in the developing rat ovary. Endocrinology 146: 5267-5277.

44. Rajkovic A, Pangas SA, Ballow D, Suzumori N, Matzuk MM (2004) NOBOX deficiency disrupts early folliculogenesis and oocyte-specific gene expression. Science 305: 1157-1159.

45. Reddy P, Shen L, Ren C, Boman K, Lundin E, et al. (2005) Activation of Akt $(\mathrm{PKB})$ and suppression of FKHRL1 in mouse and rat oocytes by stem cell factor during follicular activation and development. Dev Biol 281: 160-170.

46. Soyal SM, Amleh A, Dean J (2000) FIGalpha, a germ cell-specific transcription factor required for ovarian follicle formation. Development 127: 4645-4654.

47. Wang N, Zhang P, Guo X, Zhou Z, Sha J (2011) Hnrnpk, a protein differentially expressed in immature rat ovarian development, is required for normal primordial follicle assembly and development. Endocrinology 152: 1024-1035.

48. Rajah R, Glaser EM, Hirshfield AN (1992) The changing architecture of the neonatal rat ovary during histogenesis. Dev Dyn 194: 177-192.

49. Shaikh AA (1971) Estrone and estradiol levels in the ovarian venous blood from rats during the estrous cycle and pregnancy. Biol Reprod 5: 297-307.

50. Bertolasio J, Fyfe S, Snyder BW, Davis AM (2011) Neonatal injections of methoxychlor decrease adult rat female reproductive behavior. Neurotoxicology 32: 809-813.

51. Kato H, Ota T, Furuhashi T, Ohta Y, Iguchi T (2003) Changes in reproductive organs of female rats treated with bisphenol A during the neonatal period. Reprod Toxicol 17: 283-288.

52. Navarro VM, Sanchez-Garrido MA, Castellano JM, Roa J, Garcia-Galiano D, et al. (2009) Persistent impairment of hypothalamic KiSS-1 system after exposures to estrogenic compounds at critical periods of brain sex differentiation. Endocrinology 150: 2359-2367.

53. Patisaul HB, Losa-Ward SM, Todd KL, McCaffrey KA, Mickens JA (2012) Influence of ERbeta selective agonism during the neonatal period on the sexual differentiation of the rat hypothalamic-pituitary-gonadal (HPG) axis. Biol Sex Differ 3: 2 .

54. Shibutani M, Masutomi N, Uneyama C, Abe N, Takagi H, et al. (2005) Downregulation of GAT-1 mRNA expression in the microdissected hypothalamic medial preoptic area of rat offspring exposed maternally to ethinylestradiol. Toxicology 208: 35-48

55. Oriowo MA, Landgren BM, Stenstrom B, Diczfalusy E (1980) A comparison of the pharmacokinetic properties of three estradiol esters. Contraception 21: 415424 .

56. Weniger JP, Zeis A, Chouraqui J (1993) Estrogen production by fetal and infantile rat ovaries. Reprod Nutr Dev 33: 129-136.

57. Zhu BT, Conney AH (1998) Functional role of estrogen metabolism in target cells: review and perspectives. Carcinogenesis 19: 1-27.

58. Suchar LA, Chang RL, Thomas PE, Rosen RT, Lech J, et al. (1996) Effects of phenobarbital, dexamethasone, and 3-methylcholanthrene administration on the metabolism of 17 beta-estradiol by liver microsomes from female rats. Endocrinology 137: 663-676.

59. You L, Chan SK, Bruce JM, Archibeque-Engle S, Casanova M, et al. (1999) Modulation of testosterone-metabolizing hepatic cytochrome P-450 enzymes in developing Sprague-Dawley rats following in utero exposure to $\mathrm{p}$, p'-DDE. Toxicol Appl Pharmacol 158: 197-205.

60. Raftogianis R, Creveling C, Weinshilboum R, Weisz J (2000) Estrogen metabolism by conjugation. J Natl Cancer Inst Monogr: 113-124.

61. Lievertz RW (1987) Pharmacology and pharmacokinetics of estrogens. Am J Obstet Gynecol 156: 1289-1293.

62. Chapple RH, Tizioto PC, Wells KD, Givan SA, Kim J, et al. (2013) Characterization of the rat developmental liver transcriptome. Physiol Genomics 45: 301-311.

63. Odum J, Orton TC (1983) Hepatic microsomal glucuronidation of clofibric acid in the adult and neonate albino rat. Biochem Pharmacol 32: 3565-3569.

64. Blair IA (2010) Analysis of estrogens in serum and plasma from postmenopausal women: past present, and future. Steroids 75: 297-306.

65. Lepine J, Bernard O, Plante M, Tetu B, Pelletier G, et al. (2004) Specificity and regioselectivity of the conjugation of estradiol, estrone, and their catecholestrogen and methoxyestrogen metabolites by human uridine diphospho-glucuronosyltransferases expressed in endometrium. J Clin Endocrinol Metab 89: 5222 5232.

66. Ritter JK (2000) Roles of glucuronidation and UDP-glucuronosyltransferases in xenobiotic bioactivation reactions. Chem Biol Interact 129: 171-193.

67. Luu-The V, Pelletier G, Labrie F (2005) Quantitative appreciation of steroidogenic gene expression in mouse tissues: new roles for type 25 alphareductase, 20alpha-hydroxysteroid dehydrogenase and estrogen sulfotransferase. J Steroid Biochem Mol Biol 93: 269-276.

68. Gershon E, Hourvitz A, Reikhav S, Maman E, Dekel N (2007) Low expression of COX-2, reduced cumulus expansion, and impaired ovulation in SULT1E1deficient mice. Faseb J 21: 1893-1901.

69. Udomsuk L, Jarukamjorn K, Putalun W, Sakuma T, Kawasaki Y, et al. (2011) Modified expression of aryl hydrocarbon receptor-related genes by deoxymiroestrol, a phytoestrogen, in mouse hepatocytes in primary culture. J Ethnopharmacol 137: 902-908.
70. Deb S, Tai JK, Leung GS, Chang TK, Bandiera SM (2011) Estradiol-mediated suppression of CYP1B1 expression in mouse MA-10 Leydig cells is independent of protein kinase A and estrogen receptor. Mol Cell Biochem 358: 387-395.

71. Leung GS, Kawai M, TaiJK, Chen J, Bandiera SM, et al. (2009) Developmental expression and endocrine regulation of CYP1B 1 in rat testis. Drug Metab Dispos 37: $523-528$.

72. Wiegand H, Wagner AE, Boesch-Saadatmandi C, Kruse HP, Kulling S, et al. (2009) Effect of dietary genistein on Phase II and antioxidant enzymes in rat liver. Cancer Genomics Proteomics 6: 85-92.

73. Buckley DB, Klaassen CD (2009) Mechanism of gender-divergent UDPglucuronosyltransferase mRNA expression in mouse liver and kidney. Drug Metab Dispos 37: 834-840.

74. Diel P (2002) Tissue-specific estrogenic response and molecular mechanisms. Toxicol Lett 127: 217-224.

75. Singhal R, Shankar K, Badger TM, Ronis MJ (2009) Hepatic gene expression following consumption of soy protein isolate in female Sprague-Dawley rats differs from that produced by $17\{$ beta $\}$-estradiol treatment. J Endocrinol 202: $141-152$.

76. Stahlberg N, Merino R, Hernandez LH, Fernandez-Perez L, Sandelin A, et al. (2005) Exploring hepatic hormone actions using a compilation of gene expression profiles. BMC Physiol 5: 8.

77. Naciff JM, Hess KA, Overmann GJ, Torontali SM, Carr GJ, et al. (2005) Gene expression changes induced in the testis by transplacental exposure to high and low doses of 17 alpha\}-ethynyl estradiol, genistein, or bisphenol A. Toxicol Sci 86: $396-416$.

78. Naciff JM, Overmann GJ, Torontali SM, Carr GJ, Khambatta ZS, et al. (2007) Uterine temporal response to acute exposure to 17alpha-ethinyl estradiol in the immature rat. Toxicol Sci 97: 467-490.

79. Akinola LA, Poutanen M, Vihko R, Vihko P (1997) Expression of 17betahydroxysteroid dehydrogenase type 1 and type 2, P450 aromatase, and 20alphahydroxysteroid dehydrogenase enzymes in immature, mature, and pregnant rats. Endocrinology 138: 2886-2892.

80. Kuiper GG, Carlsson B, Grandien K, Enmark E, Haggblad J, et al. (1997) Comparison of the ligand binding specificity and transcript tissue distribution of estrogen receptors alpha and beta. Endocrinology 138: 863-870.

81. Mowa CN, Iwanaga T (2000) Developmental changes of the oestrogen receptoralpha and -beta mRNAs in the female reproductive organ of the rat-an analysis by in situ hybridization. J Endocrinol 167: 363-369.

82. Sar M, Welsch F (1999) Differential expression of estrogen receptor-beta and estrogen receptor-alpha in the rat ovary. Endocrinology 140: 963-971.

83. Hazell GG, Yao ST, Roper JA, Prossnitz ER, O’Carroll AM, et al. (2009) Localisation of GPR30, a novel G protein-coupled oestrogen receptor, suggests multiple functions in rodent brain and peripheral tissues. J Endocrinol 202: 223236.

84. Ikeda Y, Nagai A, Ikeda MA, Hayashi S (2002) Increased expression of Mullerian-inhibiting substance correlates with inhibition of follicular growth in the developing ovary of rats treated with E2 benzoate. Endocrinology 143: 304 312 .

85. De Pol A, Benelli A, Arletti R, Cavazzuti E, Sena P, et al, (2001) Influence of estrogens and oxytocin on germ cells death in the neonatal mammalian ovary. Ital J Anat Embryol 106: 233-239.

86. Kim H, Nakajima T, Hayashi S, Chambon P, Watanabe H, et al. (2009) Effects of diethylstilbestrol on programmed oocyte death and induction of polyovular follicles in neonatal mouse ovaries. Biol Reprod 81: 1002-1009.

87. Marzona L, Arletti R, Benelli A, Sena P, De Pol A (2001) Effects of estrogens and oxytocin on the development of neonatal mammalian ovary. In Vivo 15: 271-279.

88. Karavan JR, Pepling ME (2012) Effects of estrogenic compounds on neonatal oocyte development. Reprod Toxicol 34: 51-56.

89. Kipp JL, Kilen SM, Bristol-Gould S, Woodruff TK, Mayo KE (2007) Neonatal exposure to estrogens suppresses activin expression and signaling in the mouse ovary. Endocrinology 148: 1968-1976.

90. Jefferson WN, Couse JF, Banks EP, Korach KS, Newbold RR (2000) Expression of estrogen receptor beta is developmentally regulated in reproductive tissues of male and female mice. Biol Reprod 62: 310-317.

91. Gawriluk TR, Hale AN, Flaws JA, Dillon CP, Green DR, et al. (2011) Autophagy is a cell survival program for female germ cells in the murine ovary. Reproduction 141: 759-765.

92. Brieno-Enriquez MA, Robles P, Camats-Tarruella N, Garcia-Cruz R, Roig I, et al. (2011) Human meiotic progression and recombination are affected by Bisphenol A exposure during in vitro human oocyte development. Hum Reprod 26: $2807-2818$.

93. Zhang HQ, Zhang XF, Zhang LJ, Chao HH, Pan B, et al. (2012) Fetal exposure to bisphenol A affects the primordial follicle formation by inhibiting the meiotic progression of oocytes. Mol Biol Rep 39: 5651-5657.

94. Choi Y, Oin Y, Berger MF, Ballow DJ, Bulyk ML, et al. (2007) Microarray analyses of newborn mouse ovaries lacking Nobox. Biol Reprod 77: 312-319.

95. Telfer E, Gosden RG (1987) A quantitative cytological study of polyovular follicles in mammalian ovaries with particular reference to the domestic bitch (Canis familiaris). J Reprod Fertil 81: 137-147.

96. Mazaud Guittot S, Guigon CJ, Coudouel N, Magre S (2006) Consequences of fetal irradiation on follicle histogenesis and early follicle development in rat ovaries. Biol Reprod 75: 749-759. 
Neonatal Estradiol Exposure Effects in the Rat

97. Guigon CJ, Coudouel N, Mazaud-Guittot S, Forest MG, Magre S (2005) Follicular cells acquire sertoli cell characteristics after oocyte loss. Endocrinology 146: 2992-3004.
98. Guigon CJ, Magre S (2006) Contribution of germ cells to the differentiation and maturation of the ovary: insights from models of germ cell depletion. Biol Reprod 74: 450-458.

99. Whitworth DJ (1998) XX germ cells: the difference between an ovary and a testis. Trends Endocrinol Metab 9: 2-6. 